\title{
ALGUNAS OBSERVACIONES SOBRE EL PROYECTO DE CONVENIO DE UNCITRAL SOBRE LA VENTA JUDICIAL DE BUQUES
}

\author{
SOME OBSERVATIONS ON THE UNCITRAL DRAFT \\ CONVENTION ON JUDICIAL SALE OF SHIPS
}

\author{
Juan Pablo Rodríguez Delgado* \\ Profesor Visitante Doctor de Derecho Mercantil \\ Universidad Carlos III de Madrid \\ ORCID ID: 0000-0001-9650-2870
}

Recibido: 21.06.2021 / Aceptado: 07.07.2021

DOI: https://doi.org/10.20318/cdt.2021.6268

\begin{abstract}
Resumen: La venta judicial de un buque representa el capítulo final de cualquier procedimiento judicial por la reclamación de deudas marítimas. La venta tiene que garantizar el mejor precio posible del buque, lo que permite que un número mayor de acreedores puedan ver satisfechos sus créditos. Este final se logrará solo si la venta confiere al comprador un "título de propiedad limpio", extinguiendo todas las cargas, derechos y reclamaciones existentes sobre el buque. Este proceso asegurará al comprador poder cancelar la inscripción registral del buque y registrar su nueva propiedad bajo una nueva bandera a su conveniencia, pudiendo navegar alrededor del mundo sin temor a ser nuevamente embargado por créditos no satisfechos. Este artículo proporciona algunos apuntes sobre el Proyecto de Instrumento sobre venta judicial de buques que está actualmente en elaboración en el seno del GT VI de UNCITRAL.

Palabras clave: venta judicial de buque, título de propiedad limpio, UNCITRAL-CNUDMI, acreedores, créditos marítimos privilegiados, hipotecas navales

Abstract: Judicial sale of a ship and distribution of the proceeds to creditors represent the final chapter of any in rem proceeding (or its equivalent in civil law jurisdictions). The judicial sale must secure the best possible price for the ship, permitting more creditors can satisfy their credits. This finality will only be achieved if the sale confers title a 'clean title' on the purchaser, extinguishing all rights and interests over the ship. This process shall ensure that the purchaser may deregister the ship from its old flag and re-register under new ownership in a new flag and sail worldwide without any concern of re-arrest. This article provides some notes on the UNCITRAL Draft Instrument on judicial sale of ships focused on the conditions for a judicial sale of a ship conducted in one State Party to have effects in another Contracting State.
\end{abstract}

Keywords: judicial sale of ship, clean title, UNCITRAL-CNUDMI, creditors, maritime liens, mortgages

${ }^{*}$ El presente artículo ha sido elaborado en el marco del Proyecto de Investigación con el título "Innovación tecnológica para la modernización de los sistemas de garantías mobiliarias: registros electrónicos, activos digitales y plataformas" financiado por el Ministerio de Economía y Competitividad (PID2019-107189GB-I00). El autor es Representante de la MAA en el Grupo de Trabajo VI de UNCITRAL-CNUDMI durante la elaboración del Proyecto de Convenio Internacional sobre Venta Judicial de Buques Of Counsel en Albors Galiano y Portales. 
Sumario: I. Introducción. II. Recorrido histórico y estructura del Proyecto de Convenio sobre venta judicial de buques. III. Condiciones para que una venta judicial nacional de buque tenga efecto internacional bajo el paraguas del Proyecto de Convenio. 1. La venta judicial debe ser ordenada por un órgano judicial de un Estado Contratante (u otra autoridad pública). 2. Que la venta se haya realizado de conformidad con la ley del Estado de venta judicial. 3. La venta debe haberse realizado conforme los requisitos de notificación establecidos en el artículo 4. 4. El buque se encontraba, en el momento de la venta, físicamente dentro del territorio del Estado de la venta judicial. A) Tipos de buques cubiertos por el Convenio. B) El buque se encontraba físicamente dentro del territorio del Estado de la venta judicial en el momento de la venta. C) Venta judicial de buque con equipamiento específico a bordo que no sea propiedad del propietario del buque: el buque como bien complejo. 5 . Ventas judiciales excluidas de la Convención: cargas e hipotecas asumidas por el comprador. 6. La venta judicial confiere al comprador un título de propiedad limpio sobre el buque conforme a la ley del Estado de venta judicial. A) La función del "clean titile” en la definición del ámbito de aplicación del Convenio. B) La definición de "título de propiedad limpio" en el Convenio. IV. Materialización de los efectos de la venta judicial. 1. Efectos en el Estado del Pabellón o de Registro (actuación del registrador). A) Venta judicial de un buque arrendado a casco desnudo. 2. Efectos en otro Estado Parte (no se debe volver a detener el buque después de la venta judicial). 3. Circunstancias en las que una venta Judicial no surte efectos internacionales. V. Consideraciones finales.

\section{Introducción}

1. A menudo, los propietarios y armadores de un buque se ven envueltos en situaciones de insolvencia con varios acreedores que van desde acreedores hipotecarios hasta diferentes proveedores y suministradores de bienes o servicios necesarios para la navegación. Ante esta situación, los acreedores suelen rastrear el buque hasta una jurisdicción donde pueden embargarlo fácilmente en aras a recuperar su crédito mediante su venta forzosa. Una vez que los acreedores han obtenido una sentencia favorable, y mientras el propietario o armador permanecen en mora, los acreedores deben hacer cumplir sus sentencias contra el buque, lo que invariablemente conduce a la venta judicial por subasta del activo para que los acreedores puedan recibir el pago con el producto de la venta.

2. Una vez que el acreedor hipotecario (generalmente una institución financiera internacional) tiene libertad para proceder con la ejecución de su crédito, lo hará a menudo mediante una venta judicial, ya sea recurriendo a una subasta pública o, principalmente en jurisdicciones de derecho común, mediante una venta privada aprobada y supervisada por un Tribunal. Si el acreedor hipotecario opta por ejecutar el reclamo mediante una venta judicial, la venta se realizará por el órgano judicial competente y el buque se venderá libre de cargas y gravámenes al mejor postor. Cuando esta etapa "desafortunada" llega, lo más importante es que el buque obtenga el mejor precio en el menor tiempo posible para los acreedores (registrados y no registrados) así como para el propietario original.

3. El reconocimiento internacional de las ventas judiciales surge de la absoluta necesidad de asegurar que cuando, luego de un embargo, el adquirente obtiene un título de propiedad sobre el buque libre de cargas para proceder a su uso, como un eslabón integral en la cadena del comercio internacional, sin temor a que antiguos acreedores puedan solicitar embargos posteriores e interferir así con su libre uso.

4. La venta judicial de un buque tiene, en la mayoría de las jurisdicciones, dos efectos importantes: en primer lugar, transferir la propiedad del buque al nuevo comprador; $y$, en segundo lugar, purgar todas las cargas e hipotecas existentes sobre el buque, transfiriendo dichos créditos al producto de la venta. Ambos efectos se pueden resumir con la expresión utilizada por el Convenio "título de propiedad limpio": "título" respecto a la transferencia de propiedad al nuevo propietario y "limpio" respecto a la purga de cargas previas que opera con la venta.

5. El buque sigue existiendo teóricamente en la forma de un fondo que representa el producto de la venta en los tribunales, un fondo en el que los propietarios poseen un interés residual en el caso, a menudo improbable, de que exista un excedente de dinero después de la satisfacción de todas las 
reclamaciones probadas. Pero, si el producto no fuera suficiente para pagar a todos los acreedores, se mantendrá la reclamación personal contra el propietario del buque.

6. Que el buque se venda libre y sin gravámenes asegura en la mayoría de los casos que el comprador puede cancelar y dar de baja el buque de su anterior bandera y volver a registrarlo con una nueva propiedad en un nuevo registro y nueva nacionalidad sin problema alguno. De esta manera, el comprador puede navegar por todo el mundo sin preocupación de volver a ser embargado por algún acreedor que no fue notificado de la venta judicial (o que incluso siéndolo, su crédito no fue totalmente satisfecho con el producto de la venta). La certidumbre que los operadores marítimos reclaman requiere un "fresh start" por su nuevo propietario respecto de las deudas existentes sobre el buque.

7. La materialización de estos efectos internacionales es: (1) a solicitud del comprador, el Registrador -en el Estado donde está matriculado el buque- cancelará cualquier hipoteca o carga registrada sobre al buque, y eliminará del registro la inscripción de este, para emitir un certificado de baja con el propósito de que el propietario pueda proceder a una nueva matrícula en el registro de su conveniencia; y (2) el Tribunal de un Estado Contratante desestimará la solicitud de embargo, o liberará el buque si este ya ha sido embargado, cuando se le certifique la venta judicial previa.

8. En la actualidad no existen instrumentos marítimos uniformes sobre las ventas judiciales (excepto por la escasa adopción ${ }^{1}$ de los Convenio sobre Privilegios Marítimos e Hipotecas navales de 1993 -en adelante, MLMC 1993- y de 1926, que contienen algunas normas sobre la venta forzosa de buques $^{2}$ ). Las decisiones judiciales de venta sobre el buque se dictan de conformidad con la legislación nacional y, como tales, no tienen efectos extraterritoriales automáticos, a excepción de los tratados bilaterales de reconocimiento de sentencias entre Estados o, en el caso de la Unión Europea, el Reglamento de Bruselas I ${ }^{3}$ y el Convenio de Lugano de 2007. La capacidad práctica del tribunal para otorgar un título de propiedad limpio que sean reconocido internacionalmente y pueda así desplegar todos sus efectos depende, en la actualidad, del grado de cooperación y reconocimiento internacional ${ }^{4}$.

9. Un Convenio como el propuesto por el CMI (y bajo la redacción actual de UNCITRAL) no solo favorecerá los intereses de los nuevos adquirentes, sino también a sus financiadores, que necesitan la seguridad de que el buque que están a punto de financiar está limpio de toda carga, para certificar que desde ese momento son los únicos y primeros acreedores. Esta certiumbre y el incremento del precio de la venta favorecerán igualmente al resto de acreedores -especialmente los acreedores marítimos privilegiados- que verán incrementadas sus opciones de recuperar su crédito tras la venta judicial.

\section{Recorrido histórico y estructura del Proyecto de Convenio sobre venta judicial de buques}

10. El Proyecto de Convenio sobre Venta Judicial de Buques se remonta a un documento presentado por el profesor Henry Hai Li en 2007 en el que llamó la atención sobre los problemas que surgían en muchas jurisdicciones por la falta de reconocimiento de sentencias extranjeras que ordenaban la venta judicial de un buque ${ }^{5}$. Ante estos hechos, el Consejo Ejecutivo de CMI propuso que un Grupo de Trabajo Internacional realizara un estudio preliminar sobre la materia.

\footnotetext{
${ }^{1}$ Con tan sólo 18 Estados Contratantes es de destacar que entre estos no se encuentra ningún Estado del common law, ningún Estado financiador (como Reino Unido, EE.UU. o Japón), Estados de bandera (Panamá o Liberia), Estados constructores (Corea, China o Japón) y sólo tres Estados europeos.

${ }^{2}$ Artículo 13 del MLMC 1993.

${ }^{3}$ El Reglamento (UE) 1215/2012 relativo a la competencia judicial, el reconocimiento y la ejecución de resoluciones judiciales en materia civil y mercantil.

${ }^{4}$ P. Myburgh, "Satisfactory for its own purposes: private direct arrangements and judicial vessel sales", CML Working Paper Series, vol. 17/01, 2017.

${ }^{5}$ Publicado en el CMI Yearbook 2009, pp. 342-56.
} 
11. Tras varias reuniones, coloquios y sesiones de trabajo (Buenos Aires 2010, Beijing 2012 -que da nombre al borrador del instrumento-, Dublín 2013 y Hamburgo 2014), el CMI consideró que un instrumento internacional llenaría el vacío dejado en esta materia por la escasa ratificación del MLMC 1993; y cubriría las necesidades comerciales que la industria marítima parecía requerir.

12. Tras varios intentos de patrocinio del Proyecto (la OMI en 2015 o la Conferencia de La Haya en 2016), se consideró que la CNUDMI era el foro apropiado para llevar a cabo esta labor legislativa (dada su dilatada experiencia legislativa en materias relativas a la insolvencia transfronteriza, Derecho marítimo o garantías mobiliarias). En su $51^{\circ}$ período de sesiones, la Comisión de la CNUDMI se comprometió a desarrollar un instrumento internacional sobre venta judicial de buques y su reconocimiento internacional, encargando su elaboración al Grupo de Trabajo VI. El trabajo previo del CMI proporcionó un punto de partida útil y adecuado.

13. Después de varias sesiones del GT VI (mayo de 2019; noviembre de 2019; diciembre 2020 y abril 2021), el texto parece que va llegando a su redacción definitiva.

14. Si bien el Proyecto de Beijín fue concebido originalmente como una Convención (y en esa forma fue presentado por el CMI), durante las primeras sesiones algunas delegaciones propusieron la posibilidad de que el instrumento tomara la forma de una ley modelo. Sin embargo, hay un amplio apoyo para seguir trabajando sobre el supuesto de que el Instrumento tomará finalmente la forma de Convención.

15. La redacción actual del Instrumento (tras la tercera revisión del A/CN.9/WG.VI/WP.90), después de varias revisiones del borrador original, tiene la siguiente estructura:

- Una primera parte dedicada a la finalidad y propósito de la Convención (Artículo 1), junto con un artículo relativo a las definiciones -cuya extensión se ha reducido en cada nueva versión- (Artículo 2) y el ámbito de aplicación del Instrumento (Artículo 3), sin duda, uno de los artículos más importantes y discutidos del texto.

- Una segunda parte, que podríamos denominar "fase previa a la venta judicial”, está dedicada a cuestiones sobre la notificación de la venta a los interesados (y al Repositorio), bajo las normas procesales del Estado donde se realiza la venta (Artículo 4 y artículo 12).

- Y una tercera fase, denominada "fase post venta judicial", y que ocupa la mayor parte de disposiciones del Instrumento, donde se regulan las diversas materias relacionadas con los efectos internacionales: (a) el certificado de venta judicial (artículos 5 y 11); (b) los efectos internacionales de la venta (Artículos 6 a 8 y artículo 10); y (c) la suspensión o anulación de la venta judicial (Artículo 9).

16. El Instrumento deja la fase de la venta judicial, de carácter eminentemente procesal, a la Ley del Estado donde la venta tiene lugar por el Tribunal competente ${ }^{6}$.

\section{Condiciones para que una venta judicial de buque tenga efecto internacional bajo el paraguas del Proyecto de Convenio}

17. La venta judicial de un buque tiene, en la mayoría de las jurisdicciones, dos importantes efectos: (1) transfiere la propiedad del activo al nuevo comprador; $y,(2)$ purga todos los créditos, cargas y reclamaciones que existan sobre el buque. Si con el producto de la venta no fuera suficiente para re-

\footnotetext{
${ }^{6}$ Desde el inicio, los redactores del Proyecto de Beijing reconocieron la imposibilidad de armonizar temas sobre procedimientos civiles en un instrumento internacional cuyo propósito es atraer el mayor número de Estados hacia su ratificación, centrando su atención en el reconocimiento de los efectos internacionales de la venta en los Estados Contratantes, en lugar de dedicar parte de sus disposiciones regular el procedimiento de venta judicial como tal (a excepción del artículo 4 sobre la notificación).
} 
sarcir a todos los acreedores, siempre perduraría la reclamación "in personam" contra el deudor (ya sea propietario registral del buque o armador no propietario) $)^{7}$. Ambos efectos se pueden resumir con la expresión utilizada por el Instrumento de la CNUDMI "título de propiedad limpio" o "clean title" ("título" en relación con la transferencia de propiedad del deudor al nuevo comprador por motivo de la venta, y "limpio" en relación con las cargas previas que se extinguen con la venta judicial).

18. Las condiciones para que una venta judicial de un buque realizada en un Estado Parte tenga efectos internacionales en otro Estado Parte, de conformidad con los términos del futuro Convenio, son:

1. La venta debe ser ordenada, aprobada o ratificada por un órgano judicial de un Estado Contratante (u otra autoridad pública designada a tal efecto), ya sea en subasta pública (by auction) o mediante acuerdo de las partes (private treaty) realizado bajo la supervisión y con la aprobación de un órgano judicial (Artículo 2.c.i);

2. Que la venta se haya realizado de conformidad con la ley del Estado de venta judicial (Artículo 3.1.b);

3. La venta debe haberse realizado conforme los requisitos de notificación establecidos en el artículo 4 (Artículo 6);

4. El buque se encontraba, en el momento de la venta, físicamente dentro del territorio del Estado de la venta judicial (Artículo 3.1.a);

5. El producto de esa venta se ponga a disposición de los acreedores, de conformidad con la ley del Estado de venta judicial (Artículo 2.c.ii); y

6. La venta judicial ha de conferir al adquirente "título de propiedad limpio" sobre el buque (Artículo 3.1.b).

19. Si estos requisitos se cumplen, la venta judicial llevada a cabo en un Estado Parte entrará en del ámbito de aplicación del Convenio y éste desplegará sus efectos internacionales en el resto de Estados Contratantes.

\section{La venta judicial debe ser ordenada por un órgano judicial de un Estado Contratante (u otra autoridad pública)}

20. Para que el Convenio desplegue sus efectos sobre una venta judicial de un buque -y tras varias modificaciones sobre este requisito-, ésta debe ser ordenada, aprobada o ratificada por un tribunal de un Estado Contratante (u otra autoridad pública), ya sea ${ }^{8}$ :

1. mediante subasta pública [tras varios intentos, parece que se ha suprimido definitivamente del texto actual la exclusión de las "ventas realizadas tras el apresamiento o decomisa de un buque por autoridades fiscales o aduaneras" $"$; o

\footnotetext{
${ }^{7}$ Las obligaciones que incumben "in personam" al propietario del buque no se ven afectadas por la venta judicial y, por lo tanto, no se extinguen tras esta, ya que no están afectadas al buque. Se ha recordado reiteradamente que el instrumento no afecta a ningún crédito in personam que pudiera existir contra el anterior propietario del buque en virtud del Derecho interno y que tampoco crea ningún crédito in personam si tal crédito no existía o si se había extinguido de conformidad con el Derecho interno.

${ }^{8}$ Algunas delegaciones han propuesto definir el término "autoridad competente", dado que este puede ser utilizado para hacer referencia a tres autoridades diferentes, a saber: a) la autoridad que ordenaba la venta judicial, b) la autoridad encargada de realizar la venta judicial y c) la autoridad que expedía el certificado de venta judicial. Si bien se ha reconocido la necesidad de que el Instrumento respetara la diversidad de autoridades que intervenían en las ventas judiciales según los distintos ordenamientos jurídicos nacionales (A/CN.9/973 par. 83).

${ }^{9}$ En la segunda versión revisada se preveían dos exclusiones del ámbito de aplicación del Convenio: las ventas realizadas tras el apresamiento o decomiso de un buque por autoridades fiscales o aduaneras u otras autoridades encargadas de asegurar el cumplimiento de la ley (Artículo 3.2(a)) y los buques de propiedad de un Estado (Artículo 3.2(b)). En el $37^{\circ}$ período de sesiones el GT decidió por amplia mayoría a suprimir la primera exclusión.
} 
2. por acuerdo privado realizado bajo la supervisión y con la aprobación de un tribunal (ya que en varias jurisdicciones se reconoce una venta por tratado privado y una referencia a este método de venta judicial). Sin embargo, el GT acordó aclarar que una venta por "tratado privado" no es una venta privada sino más bien una venta realizada bajo la supervisión y con la aprobación de un tribunal ${ }^{10}$.

21. Se ha suprimido del texto actual una tercera posibilidad, contemplada en el Proyecto de Beijín, que permitiría una venta "por cualquier otro medio previsto por la ley del Estado de venta judicial". En la práctica, sin embargo, la mayoría de los buques se subastan públicamente o se venden mediante acuerdo privado entre las partes, por lo que este método alternativo siempre fue residual.

\section{Que la venta se haya realizado de conformidad con la ley del Estado de venta judicial}

22. La segunda condición para que una venta judicial de un buque tenga efectos internacionales conforme a la Convención -y, por tanto, para que sea posible la emisión del certificado de venta judiciales que esta se haya realizado de conformidad con la ley del Estado de venta judicial.

23. La ley del Estado en el que se lleva a cabo la venta judicial es la ley que determinará si confiere "título de propiedad limpio" según el significado del Convenio. Si el Estado de la venta judicial -siendo $\mathrm{EC}^{11}$ - otorga al comprador título limpio sobre el buque, entonces se aplica el Convenio; pero, aunque el Estado de la venta sea Estado Parte, si esa venta en particular no purga las cargas previas -por tanto, no confiere un título de propiedad limpio-, entonces la venta estará fuera del ámbito de aplicación del Instrumento. No se emitirá, por tanto, un Certificado de Venta Judicial de acuerdo con el Artículo 5, y esta no podrá desplegar sus efectos internacionales.

24. El artículo 5 prescribe cuatro condiciones -muy similares a las ya enunciadas para la aplicación de la Convención a una venta judicial- para la emisión en favor del comprador del certificado de venta judicial $^{12}$ (no para la validez de la venta judicial, que debe ser prescrita por la ley del Estado de la venta):

a) que la venta del buque se haya realizado de conformidad con la ley del Estado de venta judicial,

\footnotetext{
${ }^{10} \mathrm{~A} / \mathrm{CN} .9 / 1007$.

${ }^{11}$ La mayoría de las delegaciones han optado, sobre la base del principio de reciprocidad, por admitir el régimen de reconocimiento sólo a las ventas judiciales realizadas en un Estado Parte de la Convención (Artículo 1), expresando preferencia por un régimen de aplicación "cerrado" (tanto el Estado de la venta como los Estados donde se produzcan los efectos del Convenio deben ser Estados Contratantes).

${ }^{12}$ La presentación del Certificado implicará su reconocimiento automático por parte del Registro de un Estado Contratante encargado de la baja registral del buque. Tal es este efecto que el certificado de venta judicial a que se hace referencia en el artículo 5 estará exento de legalización u otra formalidad similar. El Grupo de Trabajo ha señalado que el certificado de venta judicial es por lo general un documento público en el sentido de lo dispuesto en el Convenio sobre la Eliminación del Requisito de la Legalización de Documentos Públicos Extranjeros de 1961 ("Convenio sobre la Apostilla") y que, por lo tanto, quedará exento del requisito de legalización previsto en el art. 2 de ese Convenio entre los más de 100 Estados parte en el Convenio. El Convenio de 1993 ya incorporó un certificado que acreditaba la válida venta del buque libre de toda hipoteca, mortgage o gravamen tras cumplir con los trámites exigidos por el Convenio y la normativa interna (art. 12.5 del Convenio). En palabras del Prof. Gabaldón, "particular interés posee, para la agilización del tráfico, el régimen del número 5 del artículo 12. A tenor de dicho precepto los registradores de los Estados Parte están obligados a cancelar todos los gravámenes inscritos (siempre a salvo de los tomados a su cargo por el comprador) y a inscribir el buque a nombre del adjudicatario o, en su caso, a librar certificación de baja a efectos de nueva matriculación. Basta por ello con que el interesado presente el certificado de venta forzosa, librado por la autoridad del Estado Parte que ha ejecutado la venta. En otras palabras, la escritura o documento público de venta judicial o administrativa es título suficiente, sin necesidad de exequatur, para que los registradores de los Estados Parte (en nuestro caso el Registro Mercantil competente) practiquen las pertinentes inscripciones, cancelaciones o bajas registrales" (Vid. J.L. Gabaldón GarCí, "El Convenio Internacional sobre privilegios marítimos e hipoteca naval, Ginebra, 6 de mayo de 1993", en J. L. Iglesias Prada (dir.), Estudios jurídicos en homenaje al profesor Aurelio Menéndez. T. III. Contratos mercantiles, Derecho Concursal y Derecho de la Navegación, Civitas, Madrid, 1996, p. 3762).
} 
(b) que la venta se haya realizado de conformidad con los requisitos de notificación del artículo 4 ,

(c) que el buque se encontrase físicamente dentro del territorio del Estado de venta judicial en el momento de dicha venta,

(d) que el comprador adquiriese un título de propiedad limpio sobre el buque por razón de la venta $^{13}$.

25. La expedición de este Certificado ser hará (a) de oficio o a petición del comprador (si bien hay un gran apoyo a que la expedición sea automática), (b) de conformidad con las reglamentaciones y procedimientos del Estado emisor (que es el de la venta judicial), (c) conforme al modelo que figura en el Anexo II del Instrumento, y (d) una vez "finalizada la venta" efectuada por el comprador de conformidad con la ley del Estado de la venta ${ }^{14}$.

26. Se expresaron opiniones divergentes sobre las dos opciones propuestas en el Artículo 5.1 (A/CN.9/WG.VI/WP.90) para insertar una condición adicional sobre el carácter definitivo o firme de la venta judicial en la que el certificado solo se emitirá si la venta ya no está sujeta a ningún procedimiento de apelación dentro del período de tiempo aplicable de acuerdo con la ley del Estado de venta judicial. La posibilidad de impugnar la venta -en caso de no firmeza de la resolución- después de la emisión del certificado daría lugar al tipo de incertidumbre que la Convención pretende erradicar. Esta situación de inseguridad jurídica afectaría no solo al nuevo propietario del buque, sino a todas las partes involucradas en la cadena de eventos posterior a la producción del certificado. En términos prácticos, es poco probable que surja la cuestión de la falta de firmeza si el Tribunal que supervisa la venta judicial era también la autoridad que expide el certificado, ya que normalmente esta se habría cerciorado de que el procedimiento había concluido. La finalización de la venta ya estaba asumida por el Artículo 5.1(c), que requería que el certificado registrara que el comprador había adquirido el título de propiedad limpio sobre el buque.

27. Se expresó un amplio apoyo a la opinión de que la firmeza de una venta judicial era una cuestión que debía definirse en la ley del Estado de la venta judicial. En derecho español, por ejemplo, el Tribunal sólo emitirá el "decreto de adjudicación" del bien (título pleno para la anotación de la compraventa y traspaso de la propiedad del bien objeto de la subasta) una vez transcurrido el plazo otorgado a las partes para el posible recurso (Artículo 451 LEC). Emitido el decreto de adjudicación, el comprador podrá solicitar al Tribunal el Certificado conforme el artículo 5.

28. En consecuencia, el Grupo de Trabajo ha convenido en modificar la redacción del encabezamiento artículo 5 de la siguiente manera: "Una vez finalizada la venta efectuada al comprador de conformidad con la ley del Estado de la venta judicial, la autoridad pública designada por dicho Estado expedirá, de conformidad con sus reglamentaciones y procedimiento, un certificado de venta judicial al comprador en el que conste [...]".

\section{La venta debe haberse realizado conforme los requisitos de notificación establecidos en el ar- tículo 4.}

29. La condición prevista en el artículo 6 de que la venta judicial se realice de conformidad con los requisitos de notificación establecidos en el artículo 4 se recoge en el Instrumento desde su primera versión (A/CN.9/WG.VI/WP.84). Sin embargo, ha sido puesta recientemente en tela de juicio dada la inquietud por parte de algunas delegaciones de que esa condición expondría a la venta judicial al riesgo de ser impugnada fuera del Estado de la venta, lo que es claramente incompatible con lo dispuesto en el

\footnotetext{
${ }^{13}$ El requisito de que el certificado se haya emitido a petición del comprador se ha eliminado de la tercera revisión del Instrumento.

${ }^{14}$ El concepto de "finalización" no debe entenderse, sin embargo, como la realización todos los actos que un comprador puede desear llevar a cabo en atención a la venta judicial, como son la cancelación de la inscripción del buque en el registro y su reinscripción.
} 
artículo 9 (que confiere a los órganos judiciales del Estado de la venta judicial competencia exclusiva para conocer de las impugnaciones relacionadas con el procedimiento utilizado) y en el artículo 10 (que prevé la denegación de los efectos internacionales de la venta judicial exclusivamente por motivos de orden público), sobre la base de que dejaría a las autoridades del Estado de efecto (distintas del Estado de la venta judicial) la oportunidad de escudriñar si se han cumplido estos requisitos, la mayoría de los cuales habrían tenido lugar fuera de su jurisdicción.

30. Esto impondría una carga adicional al Registrador (junto a la obligación de registrar el buque y dar de baja el asiento previo) o los Tribunales (con respecto a la obligación de liberar el embargo del buque tras la venta) en esos otros Estados, lo que requeriría una evaluación de la legislación extranjera y la determinación de los hechos más fácilmente establecidos en el Estado de venta judicial. Todos ellos, a su vez, podrían socavar la eficacia del régimen de reconocimiento internacional en el marco del Instrumento.

31. La opinión predominante en la $38^{\mathrm{a}}$ sesión del GT fue que los requisitos de notificación no debían utilizarse como condición independiente, sino que debían leerse junto con los del artículo 5 . A tal fin se ha propuesto eliminara la condición y que, por consiguiente, se modificará el artículo 6 a fin de suprimir las palabras "siempre y cuando la venta judicial se realice de conformidad con los requisitos de notificación establecidos en el artículo 4"15.

\section{El buque se encontraba, en el momento de la venta, físicamente dentro del territorio del Estado de la venta judicial}

\section{A) Tipos de buques cubiertos por el Convenio}

32. A efectos del Convenio, por "buque" se entiende "todo buque o cualquier otra embarcación que pueda ser objeto de un embargo preventivo o cualquier otra medida similar que pueda dar lugar a una venta judicial de conformidad con la ley del Estado de la venta judicial". El GT todavía no se ha pronunciado sobre la posible necesidad de que el buque tenga que estar inscrito en un registro público como requisito para la aplicación de la Convención (Artículo 2.i) ${ }^{16}$. Se ha cuestionado durante las sesiones del Grupo de Trabajo si el Instrumento se aplicaría únicamente a la venta judicial de buques de navegación marítima o si también son objeto los buques utilizados para la navegación interior (cabotaje). Si se aplicara a los buques o embarcaciones utilizados para la navegación interior, el Instrumento colisionaría en parte con la Convención relativa a la Matriculación de Buques de Navegación Interior (1965) y su Protocolo núm. 2 relativo al Embargo y la Venta Forzosa de Buques destinados a la Navegación Interior.

33. La calificación de un buque o embarcación como "de navegación marítima" se establece en varios tratados marítimos internacionales a los que el GT se ha referido a lo largo de sus debates. Así, por ejemplo, el Convenio sobre Embargo de Buques de navegación marítima de 1952 y 1999 o el Convenio Internacional sobre Privilegios Marítimos e Hipotecas navales de 1993. En ninguno de estos Convenios se ha definido el término "buque de navegación marítima". En el contexto de esos convenios, el término depende del uso o propósito del buque más que de sus capacidades, de modo que un buque destinado a la navegación por vías navegables interiores no es "navegable" incluso si este es capaz de navegar por el mar. Un buque destinado a la navegación marítima, pese a que navegue por aguas interiores, se le considerará en navegación.

\footnotetext{
${ }^{15}$ A/CN.9/1053, párr. 20.

${ }^{16}$ Desde el principio, el GT acordó expresamente excluir del ámbito de aplicación de la Convención a los buques propiedad del Estado o operados por este y utilizados solo en servicios gubernamentales no comerciales (incluidos buques de guerra o auxiliares).
} 
34. La futura decisión del GT es aclarar si los buques de navegación interior deberían estar dentro del alcance del futuro Instrumento, o si la definición de un buque debería ser enmendada para excluir explícitamente a los buques de navegación interior (evitando así posibles conflictos con la Convención de Ginebra). La definición amplia del Artículo 2(i) puede incluir embarcaciones de recreo, buques o embarcaciones en construcción y embarcaciones de navegación interior (en lugar de aplicarse únicamente a la venta judicial de buques o embarcaciones utilizadas para navegación comercial como se sugirió al comienzo del proceso discusión del Instrumento). La mayoría de las delegaciones apoyaron mantener el Artículo 14.2 en su redacción actual, asegurando que los Estados Parte en el Convenio de Ginebra mantengan su derecho a aplicar las reglas del Convenio y su Protocolo entre ellos.

35. También se ha expresado cierto apoyo a limitar el ámbito de aplicación del Convenio solo a los buques "inscritos" (en un Registro que está abierto a la inspección pública) en un Estado Contratante. Si bien el GT no ha tomado una decisión definitiva al respecto.

36. La Convención guarda silencio sobre la venta en subasta pública por la Autoridad Portuaria de los buques hundidos o abandonados. La MLMC 1993, por su parte, permite a los Estados Contratantes establecer en su legislación que, en caso de venta forzosa de un buque varado o hundido tras su remoción por una autoridad pública, los gastos de esa remoción se pagarán con el producto de la venta antes que todos los demás créditos que estén garantizados con un privilegio maritimo sobre el buque (Artículo 12.3). Las condiciones requeridas por este párrafo son que la remoción sea efectuada por una autoridad pública y que se realice en interés de la seguridad de la navegación o de la protección del medio ambiente marino.

37. En España los arts. 302 y 304 de la LPEMM permiten a la Autoridad Portuaria, en caso de abandono (Artículo 302) o hundimiento (Artículo 304), vender esos buques en subasta pública. Una vez declarado el abandono del buque por la Autoridad Portuaria, ésta procederá a su venta, depositando el producto de la venta en el Tesoro Público (alternativamente podrá hundir el buque cuando, por su estado, razones de seguridad marítima así lo aconsejen). En principio, nada impediría que este tipo de buques, ante un proceso de venta por la Autoridad Portuaria -y bajo el cumplimiento de las condiciones previstas por el Instrumento-, pudiesen recibir el mismo trato que la Convención dispensa para el resto de las naves.

\section{B) El buque se encontraba físicamente dentro del territorio del Estado de la venta judicial en el momento de la venta}

38. El proyecto de Convenio se aplicará únicamente si el buque se encontraba (1) en el momento de la venta (2) físicamente dentro del territorio del Estado de la venta judicial (Artículo 3.1). Pese a que la soberanía de un Estado se extiende más allá de su territorio terrestre y mar territorial (en Alta Mar el buque está sujeto a la jurisdicción exclusiva de su pabellón -artículo 92 de la Convención sobre el Derecho del Mar-), esto no significa, que un buque que navega bajo la jurisdicción de su Estado de abanderamiento esté "físicamente dentro de su jurisdicción" (el uso del término "territorio" parece más adecuado al propósito del Convenio, dado que nos sitúa en un espacio físico y no legal como es el término "jurisdicción") ${ }^{17}$.

39. Durante las sesiones del GT se han expresado diferentes opiniones sobre el significado de las palabras "en el momento de la venta judicial". Para algunos Estados, el buque debe estar ubicado físicamente en el territorio del Estado de venta judicial desde el inicio hasta el final del procedimiento de venta judicial, es decir, desde el momento en que se realiza la notificación de venta hasta el momento

\footnotetext{
${ }^{17}$ En cuanto a la interpretación del requisito "dentro del territorio" existen algunas dudas sobre si el buque debe ser previamente embargado al momento de la venta, o si, por el contrario, tal situación no es un imprescindible para su posterior venta judicial conforme a la Convención.
} 
en que se transfiere la propiedad del activo al nuevo comprador. Por el contrario, en otras jurisdicciones, el buque solo necesita estar ubicado físicamente en el territorio del Estado de venta al final del procedimiento, ya que un buque podrá estar autorizado, por la autoridad pública responsable de la venta, para seguir navegando pendiente de la venta judicial efectiva.

40. En la tercera revisión del Instrumento (A/CN.9/WG.VI/WP.90), muchas delegaciones recordaron que hubo un acuerdo general en el GT para considerar que un buque se encuentra ubicado físicamente dentro del territorio del Estado de venta judicial cuando lo está en la etapa final del procedimiento, es decir, cuando ha sido adjudicado al comprador. Pero, qué sucedería si la venta judicial se inicia en un determinado Estado contratante y, durante el proceso, se autoriza por parte del Tribunal su salida para que el buque pueda seguir siendo explotado. ¿Qué sucedería? Quizás, una forma de soslayar este problema sea que el propio título de propiedad esté condicionado suspensivamente a la "arribada del buque" nuevamente al Estado donde se desarrolla la subasta pública. En cualquier caso, el "momento de la venta" se determinaría por referencia a la ley del Estado de venta judicial. Esta postura parece, sin duda, la más adecuada.

\section{C) Venta judicial de buque con equipamiento específico a bordo que no sea propiedad del propie- tario del buque: el buque como bien complejo}

41. Cuando un Convenio aborda la definición de buque, a menudo lo hace para excluir los buques de guerra, buques auxiliares u otros tipos de buques que sean propiedad del Estado o estén operados por este y se utilicen únicamente en servicios públicos gubernamentales no comerciales. Sin embargo, en determinadas circunstancias, se requiere una definición precisa e instrumental del término. Este Proyecto de Convenio es un ejemplo y una oportunidad para hacerlo. Y lo es porque, sobre el buque, la Convención despliega los efectos extintivos de todos los créditos y derecho como consecuencia de la venta judicial.

42. Dado que el buque es un bien "complejo" (formado por una pluralidad de elementos ${ }^{18}$ ), es importante distinguir, en primer lugar, si esta purga de créditos y derechos previos -incluidos los de propiedad- también contempla las partes integrantes, como componentes y los accesorios o pertenencias a bordo del buque y cuya propiedad corresponde a otra persona distinta al propietario registral; y en segundo lugar, si sobre esos componentes o accesorios, aún siendo propiedad del propietario del buque, estando gravados con algún tipo de garantía mobiliaria registrada en nombre de un tercero (un financiador o una compañía de leasing de equipos móviles, por ejemplo), se extinguen con la venta judicial.

43. La definición de partes integrantes o accesorios/componentes varía en los diferentes sistemas legales ${ }^{19}$. Una venta judicial en la que el buque en su totalidad no sea propiedad exclusiva del deudor puede dar lugar a la exclusión del ámbito de aplicación del Convenio si el "buque" no se define correctamente, dado que algunas "partes" o equipos accesorios no podrán incluirse en la venta y, por lo tanto, quedarán excluidas del reparto del producto de la venta entre los acreedores.

44. En caso de venta judicial de un buque, el propietario del equipo instalado en el buque (o un arrendador si los componentes son parte de un contrato de arrendamiento) podría querer retomar su posesión (como son los aparejos, sistemas electrónicos y de navegación, motores, grúas, botes salvavidas,

\footnotetext{
${ }^{18}$ Así, nuestra LNM lo define como bien compuesto de partes integrantes (aquellos elementos que constituyen la estructura del buque, de modo que no pueden separarse del mismo sin menoscabo de su propia entidad) y pertenencias (los elementos destinados al servicio del buque de un modo permanente, pero que no integran su estructura). Vid. Artículo 60.

${ }^{19}$ De acuerdo con la legislación española (Artículo 60 LNM), el término "buque", como bien mueble, se comprende de partes integrantes (elementos que constituyen la estructura del buque, de modo que no pueden separarse del mismo sin menoscabo de su propia entidad) y pertenencias (asignadas al servicio del buque de modo permanente). En el Reino Unido, el término utilizado es accesorios (appurtenance) y se ha sostenido que incluye todos los bienes que pertenezcan al propietario y que se encuentre a bordo (The Eurostar [1993] 1 Lloyd's Rep. 106).
} 
equipo mobiliario, etc.). Si bien la regla varía de una jurisdicción a otra, mayoritariamente la propiedad de elementos de terceros está protegida en caso de venta judicial, solicitando ante el Tribunal su derecho de propiedad mediante acción reivindicatoria (Artículo $348 \mathrm{Cc})^{20}$, dando a conocer su propiedad (adquirida antes de la incautación o la venta) ante el Tribunal (o Autoridad pública) que realiza la venta. Dado que el Convenio no regula estas cuestiones, el comprador observará cómo, durante el curso de la venta (o en algunos casos también después), terceros solicitarán que se retiren del buque algunos componentes que no sean de propiedad del propietario-deudor (lo que en algunos casos supondrá una retirada de oferentes del proceso de subasta o una disminución del precio ofrecido).

45. Por lo tanto, ¿qué sucede con esos equipos/instrumentos a bordo que no son propiedad del propietario del buque sometido en una venta judicial? ¿Qué sucede si una pieza de equipo esencial, por ejemplo, el sistema de tratamiento de agua de lastre o el equipo de navegación o comunicación que se encuentra en el buque no pertenece al propietario del buque, sino que es alquilado? ¿Debe tratar el Tribunal estos elementos como propiedad de un tercero? En tal situación, el comprador interesado puede (i) comprar el sistema a sus propietarios; (ii) retractarse de la compra del buque; o (iii) asumir el control del arrendamiento (subrogándose en la posición del anterior propietario). En el último caso, ¿Tiene su propietario derecho a reivindicarlos? ¿Obtiene el comprador un título de propiedad limpio? ¿Tiene derecho a un Certificado de venta conforme el artículo $5 ?^{21}$

46. Evidentemente, esta problemática es un asunto de la ley del Estado de venta judicial. De acuerdo con esa ley, el Tribunal decidirá el destino de tales equipos (lo que en muchos casos requerirá acudir a la norma del estado del pabellón ex artículo 10.2 Cc). En España, los negocios jurídicos sobre el buque (en los que se incluyen las ventas judiciales) comprenden las partes integrantes del buque y sus pertenencias, pero no sus accesorios (Artículo $62 \mathrm{LNM}$ ). No obstante, quedan exceptuadas las pertenecíais inscritas en el Registro de Bienes Muebles a nombre de un tercero o cuyo dominio hayas sido adquirido por él con fecha anterior a la venta judicial (Artículo 62.2 LNM). Según el artículo 134 de la LNM, la hipoteca naval comprenderá tanto las partes integrantes como sus pertenencias, salvo lo dispuesto en el artículo 62 ya mencionado, para aquellos bienes inscritos en el Registro, en cuyo caso no se incluirían en la hipoteca. Por tanto, según nuestra legislación marítima, el derecho de propiedad sobre una pertenencia, inscrita a nombre de un tercero (por ejemplo, el motor, una grúa o determinados instrumentos de navegación) no se extinguirá con la venta (como efecto purgatorio título de propiedad limpio), lo que podría conducir a que dicha venta judicial quedase fuera del ámbito de aplicación de la Convención (situando a nuestro país entre aquellos que no resultasen atractivos para este tipo de procedimientos).

\section{Ventas judiciales excluidas de la Convención: cargas e hipotecas asumidas por el comprador}

47. En la primera versión del proyecto de Instrumento (A/CN.9/WG.VI/WP.82), la venta judicial tenía como principal efecto la propiedad libre de obligaciones y gravámenes, cuya definición exceptuaba aquellas cargas que el comprador tomase a su cargo.

\footnotetext{
${ }^{20}$ Esta es la situación también en Croacia, donde los bienes pertenecientes a un tercero no están incluidos en la venta judicial y su propietario tiene derecho a sustraerlos del buque antes de su enajenación (Artículo 900 del Código Marítimo de Croacia); en Inglaterra (en The Silia [1981] 1 Lloyd's Rep. 534. en p. 537, donde la Corte sostuvo que "en el contexto de una acción real, la palabra buque incluye todos los bienes a bordo salvo aquellos cuya propiedad pertenezca a un tercero que no sea el propietario del buque". La situación es similar en Francia o Alemania y en Noruega, aunque en circunstancias más limitadas (Artículo 45 Código Marítimo).

${ }^{21}$ Cabría preguntarse si un Certificado de venta judicial emitido por el Tribunal que registra una carga sobre parte del equipo móvil del buque podría incluirse en el ámbito de aplicación del Convenio, dado que en este tipo de situaciones no es raro que el comprador haga arreglos con los acreedores (ya sean hipotecarios o arrendadores financieros de equipos móviles del buque) para hacerse cargo del reembolso de los préstamos o del precio del equipo bajo el contrato de leasing. De lo contrario, para obtener un título de propiedad limpio, el comprador tendría que otorga alguna garantía alternativa a los acreedores del equipo, permitiendo al comprador obtener un Certificado de venta judicial (así P. KRAGIC, "About the concept of Convention on judicial sale of ships", Vol. 55, ETL, 4/2020, párr. 18).
} 
48. Muchas jurisdicciones permiten la posibilidad de que en una venta judicial de un buque el comprador pueda subrogarse, con el consentimiento de los acreedores, en la hipoteca o los gravámenes inscritos existentes sobre el buque (en nuestra LNM, véase esta opción en el artículo 484) ${ }^{22}$. Considerando esta posibilidad, el Proyecto de Beijing (asumiendo la redacción del Artículo 12 MLM 1993) inicialmente exceptuó, sobre el efecto de título de propiedad limpio de obligaciones y gravámenes, aquellas que fueron "asumidas por el comprador". Tras esa primera revisión, muchas delegaciones señalaron que podría ser problemático admitir como excepción al título de propiedad limpio adquirido en virtud del Convenio los derechos "que el comprador tom [as]e a su cargo". Se mencionó como ejemplo el caso de un comprador que hubiese tomado a su cargo una hipoteca previamente inscrita y que posteriormente solicitara la inscripción del buque en otro registro y el traslado de la hipoteca al nuevo registro para su abanderamiento. Se observó que el Proyecto de Beijing no preveía que el acreedor hipotecario inscrito diera su consentimiento para el traslado de esa hipoteca, ni obligaba al registrador a cancelar la inscripción de esta.

49. Además, esta subrogación en las hipotecas existentes solo beneficiaría al acreedor hipotecario, generalmente instituciones financieras internacionales, que accedería a financiar al adjudicatario en lugar de ser reembolsado con el producto de la venta. El acreedor hipotecario ve su crédito satisfecho y beneficiado por la subrogación (cuya prioridad, que se ubicaba irremediablemente después del resto de privilegios marítimos, se ve ahora aupada a una posición privilegiada por motivo de la subrogación). Por el contrario, los acreedores marítimos verán cómo sus créditos son previsiblemente más difíciles de recuperar, debido a que el precio pagado por el adjudicatario se reducirá a la cantidad de capital cubierta por la garantía hipotecaria principal.

50. Dado que en la práctica los compradores que adquieren un buque en venta judicial no suelen tomar a su cargo las hipotecas, mortgages o gravámenes existentes, y ante la problemática "innecesaria" que podría ocasionarse, se sugirió suprimir la excepción de todas las disposiciones del proyecto de Instrumento ${ }^{23}$.

51. Uno de los problemas que podría aparecer al excluir estas ventas del ámbito de aplicación del Convenio es que en muchas ocasiones se desconoce hasta el último momento del proceso judicial si el adquirente asumirá las hipotecas o cargas anteriores, mientras que ya en ese momento procesal el Convenio ha tenido que ser aplicado (especialmente en todo lo relacionado con la notificación a las personas interesadas y al Repositorio -artículos 4 y 12-). Así, el Tribunal podría enfrentarse a la paradoja de aplicar el procedimiento de notificación del artículo 4, para luego excluir su aplicación porque el adquirente se ha subrogado en los gravámenes anteriores, $y$, por tanto, esa venta quedará excluida del ámbito de aplicación del Convenio. Por el contrario, si el Tribunal sigue los requisitos de notificación del artículo 4 (pese a no saber en ese momento si la venta judicial se incardinará en el ámbito de la Convención) y posteriormente se produce la venta sin que el comprador se subrogue en la hipoteca existente, dicha venta quedaría incluida en el ámbito de aplicación del Convenio. Podría ocurrir en ese caso que el Tribunal no cumpliese con los requisitos de notificación de la Convención, dado el desconocimiento en esa etapa del proceso si la venta estará dentro de su alcance (aplicándose el procedimiento de notificación a los interesados contemplado por la ley interna del país). Si la venta finalmente confiere un título de propiedad limpio -porque el comprador no asume los créditos anteriores-, la Convención podría considerar, para evitar innecesarias exclusiones de su aplicación, una especie de reconocimiento "oficial" de ese proceso de notificación nacional (siempre y cuando cumple unos mínimos requisitos), y evitar así posibles nulidades o suspensiones de la venta por motivos del orden público.

\footnotetext{
${ }^{22}$ También otros países como Croacia, Nigeria, Turquía o Estonia, entre otros. Ver Shipping 2019, (Kevin Cooper, Editor) Getting the deal through, 2019.

${ }^{23} \mathrm{~A} / \mathrm{CN} .9 / 973$, par. 32.
} 


\section{La venta judicial confiere al comprador un título de propiedad limpio sobre el buque conforme a la ley del Estado de venta judicial}

52. El Proyecto de Instrumento internacional no tiene por objeto el reconocimiento de las decisiones de venta de un buque en otro Estado (ya existen instrumentos internacionales para este propósito), sino el reconocimiento de los "efectos internacionales de una venta judicial", siempre que dicha venta produzca una purga total de créditos sobre el buque ${ }^{24}$. En otras palabras, esta Convención es un "espejo" en el que se deben mirar las ventas judiciales que se realicen en un Estado Contratante, materializadas de acuerdo con su legislación nacional:

a) Si el reflejo obtenido es el mismo (es decir, si hay total coincidencia en la purga total de créditos), y bajo los requisitos ya mencionados, entonces, esa venta judicial podrá expandir sus efectos internacionales sobre el adquirente en el resto de los Estados Parte una vez se haya obtenido el certificado previsto en el artículo 5 debidamente expedido (el certificado es, de hecho, condición para el reconocimiento de la venta).

b) No obstante, si la venta judicial efectuada al amparo de la ley del Estado de la venta, por cualquier motivo, no otorga una purga total de los créditos, según lo previsto por la Convención, entonces dicha venta, a pesar de ser totalmente válida y efectiva en el Estado en que se ha llevado a cabo, no podrá expandir sus efectos internacionales en el resto de Estados Contratantes (excepto sobre la base de los acuerdos de reconocimiento bilateral/regional de sentencias extranjeras).

53. Parece claro que, si el comprador que ha ofertado por el buque en una venta judicial no puede adquirir un título de propiedad libre de gravámenes, la eficacia de la venta judicial se reduciría significativamente y, como resultado, el número de oferentes dispuestos a pujar por un buque se reducirán considerablemente. Esto afectará, sin duda, al precio de la venta, lo que hará que muchos acreedores no puedan ver satisfecho su crédito con la venta, teniendo que acudir vía acciones personales (in personam claims) contra el propietario deudor.

54. En las siguientes páginas se analizarán las ventas judiciales que otorgan un título de propiedad limpio a la nave, y especialmente el significado del término "clean title" (título de propiedad limpio ${ }^{25}$ ), y qué cargas, gravámenes o derechos se extinguen con la venta judicial y cuáles no.

\section{A) La función del "clean titile" en la definición del ámbito de aplicación del Convenio}

55. Si bien en algunos Estados se sabe desde el comienzo del procedimiento de venta judicial que dicho acto confiere al comprador un título de propiedad limpio, en otros no sucede siempre así. Si la Convención finalmente se aplica únicamente a una venta judicial que confiere un título limpio sobre el buque, sería difícil para esos otros Estados cumplir con las obligaciones impuestas en virtud del artículo 4, que requiere que se notifique a determinadas personas "antes de que se proceda a una venta judicial". Se pueden considerar diferentes puntos de vista a este respecto ${ }^{26}$ :

\footnotetext{
${ }^{24}$ No sería raro que resonase en la mente del lector esas palabras del Juez Sheen en el caso Cerro Collorado "from time to time almost every shipowner wants to borrow money from his bank and to give as security a mortgage on a ship. The value of the security would be drastically reduced if, when it came to be sold by the Court there was any doubt as to whether the purchaser from the Court would get a title free of encumbrances and debts" [The "Cerro Collorado" (1993) 1 Lloyd's Rep. 58.]. En otras palabras, ninguna carga o gravamen, de la naturaleza que sea, seguirá al buque tras la venta judicial. Solo si se cumple esta condición, la venta logrará el efecto deseado, ya que nadie quiere pagar el precio de mercado por un buque si existe el riesgo de que las cargas anteriores puedan seguir siendo oponibles frente al buque tras la venta. Vid. H. HaI LI, "A Brief Discussion on Judicial Sales of Ships (paper presented at the CMI Athens Conference 2008)", CMI Yearbook, vol. 2009, p. 342.

${ }^{25}$ Durante el trabajo se utilizan indistintamente ambos términos.

${ }^{26}$ A/CN.9/1047/Rev.1, par. 39.
} 
1. Los requisitos de notificación deben aplicarse independientemente de si, en el momento pertinente, se tenía conocimiento o no que la venta judicial conferiría un título de propiedad limpio.

2. Los requisitos de notificación constituyen una condición para la emisión del Certificado de venta, y no un requisito independiente para las aplicaciones del Convenio.

3. El otorgamiento de título de propiedad limpio debe servir como condición para atribuir efectos internacionales a una venta judicial más que para definir el ámbito de aplicación del Convenio. No obstante, la opinión predominante es que el título limpio debería seguir siendo el elemento definitorio del ámbito de aplicación.

56. El entendimiento generalizado entre los redactores es que el Proyecto de Convención se aplica a las ventas judiciales realizadas en Estados donde la ley faculta al Tribunal para otorgar títulos de propiedad limpios al comprador de un buque en subasta pública (o por acuerdo privado entre las partes con supervisión y autorización judicial). En consecuencia, las ventas judiciales en las que no se otorgó un título de propiedad limpio al comprador de conformidad con la ley del Estado de venta, quedarían fuera del alcance del Instrumento.

\section{B) La definición de "título de propiedad limpio" en el Convenio}

57. La redacción actual del Artículo 2(b) del Proyecto de Instrumento -después de la tercera revisión- propone solo una opción de las dos alternativas diferentes contempladas en versiones anteriores. Aunque no existe una diferencia sustancial entre las dos alternativas presentadas, ambas difieren en algunos aspectos: Por "título de propiedad limpio" sobre un buque [a] se entenderá que se han extinguido todos los derechos de propiedad y demás derechos que existían sobre el buque antes de su venta judicial y que el buque ya no está gravado por hipotecas ni cargas; [b] se entenderá la propiedad libre y exenta de hipotecas o cargas. La primera opción detallaba claramente todos los elementos de la noción de "título limpio", si bien, incluía términos que podían ser difícilmente asimilables en otros sistemas legales. La opinión predominante dentro del Grupo de Trabajo en su tercera revisión se ha inclinado por mantener la segunda opción, que se consideró más clara, más concisa y mejor alineada con la terminología utilizada en el Proyecto de Convención ${ }^{27}$.

58. El artículo 1 del Proyecto de Beijing definía un "título de propiedad limpio" en los términos de esta segunda opción. Sin embargo, el Artículo 4.1 del Proyecto estipulaba que el efecto de una venta judicial no es solo otorgar un título limpio, sino también, en términos similares a la primera opción, extinguir todos los derechos de propiedad y demás derechos que existían sobre el buque antes de su venta judicial y que el buque, desde ese momento, ya no estará gravado por hipotecas ni cargas previas.

59. Sin embargo, la pregunta no resuelta es si el término "propiedad libre y exenta de hipotecas o cargas" purga con ello otro tipo de derechos existentes que repercuten en el buque, como son los contratos de arrendamiento a casco desnudo, los contratos de reserva de dominio, ventas condicionales o incluso, los privilegios marítimos nacionales (en virtud del artículo 6 MLMC 1993). La terminología escogida, que trata de incluir en el concepto de "clean title" el mayo número de derechos y gravámenes, otorga al sistema un grado elevado de flexibilidad y espacio para expandir su alcance a nuevas categorías distintas de las enumeradas en la definición, siempre que tengan las mismas características distintivas.

${ }^{27}$ Si bien, la primera opción diferenciaba nítidamente los "derechos de propiedad y demás derechos" que existían sobre el buque antes de su venta judicial, sobre los que el Convenio afirmaba su extinción tras la venta, de las "hipotecas ni cargas" existentes, que dejarán de gravar al buque, pero a las que el Convenio no imputa su extinción tras la venta, ya que estas cargas se transfieren al producto de la venta y dan derecho a su tenedor a participar en su distribución siguiendo las reglas de prelación que se le otorgan a cada uno de los créditos. La extinción total se produce cuando se lleva a cabo el reparto del producto de la venta. 


\section{¿Qué se incluye en el término "propiedad" (title)?}

60. Tanto el término actual "propiedad" como la expresión "todos los derechos de propiedad y demás derechos que existían sobre el buque" (en la versión anterior) significan que con la venta judicial la propiedad sobre el buque es adquirida por el nuevo comprador. En la inmensa mayoría de jurisdicciones, la venta judicial constituye base legal válida y eficaz para transferir la propiedad sobre el buque. Este es el primer y más importante efecto internacional de la venta judicial otorgada por la Convención. Todos los derechos de propiedad sobre el buque (con los matices mencionados en la definición de buque) se extinguirán (a diferencia de las cargas y gravámenes, que simplemente dejan de grabar al buque), sin perjuicio del derecho de los acreedores a obtener una compensación con el producto de la venta judicial de acuerdo con la ley del Estado donde se lleve a término (quedando a salvo, por supuesto, la acción personal contra el deudor).

\section{¿Qué "cargas" -en sentido amplio- dejan de grabar al buque en virtud de la ley del Estado de venta judicial?}

61. Durante su vida, un buque puede verse afectado por multitud de cargas y gravámenes: desde la constitución de un derecho de hipoteca para su adquisición; créditos marítimos (así, por ejemplo, salarios debidos a la tripulación, suministros impagados de combustible, tarifas portuarias debidas, costes de reparación, remolcadores, etc.); contratos a largo plazo sobre el buque (ya sean contratos de fletamentos a casco desnudo como fletamentos por tiempo o por viaje). La completa extinción sobre el buque de todos ellos, y su reconocimiento internacional, es el principal objetivo de la venta judicial propuesta por el Instrumento (sobre la base de la purga total de créditos tras la venta). Por lo que todas aquellas ventas (por subasta pública o por acuerdo de las partes con aprobación judicial), que no confieren una purga completa, quedarán fuera del alcance de la Convención. Si bien la Convención no prejuzga su validez conforme a la ley del Estado de venta, simplemente estas no estarán dentro del ámbito de la Convención.

62. El Instrumento utiliza los términos "cargas e hipotecas" (mortgages/hypothèques or charges) como términos en los que incluye todos los gravámenes que pueden afectar al buque y que deberán ser objeto de la purga. Es fundamental, pues, determinar cuál es el significado que la Convención da a cada uno de los términos:

63. Las hipotecas o mortgages se incluyen en la definición de "título de propiedad limpio". Para que la venta judicial tenga efecto extintivo de las hipotecas (dejar de embargar la nave), estas deben

a) gravar al buque;

b) estar inscrita en el Estado en cuyo registro de buques u otro registro equivalente esté inscrito el buque,

c) esté reconocida como tal por la ley que resulte aplicable de conformidad con las normas de derecho internacional privado del Estado de la venta judicial]. Limitar el término "hipoteca" a toda hipoteca "reconocida como tal por la ley que resulte aplicable de conformidad con las normas de derecho internacional privado del Estado de la venta judicial", especialmente cuando el término se utiliza para definir una obligación dirigida a Estados que no son el Estado de la venta judicial podía ocasionar problemas de reconocimiento ${ }^{28}$. Por ello, aunque se expresó cierto apoyo para mantener este requisito, una mayoría abogó por su eliminación después de la tercera revisión del Instrumento.

\footnotetext{
${ }^{28}$ La razón era que el "título de propiedad limpio" no sería reconocido por la Convención si la ley del Estado de venta judicial no reconocía una hipoteca registrada en el extranjero. Se observó que, en cualquier caso, era innecesario que el Convenio abordara el reconocimiento de hipotecas extranjeras, ya que no se ocupaba de la distribución del producto u otras cuestiones en las que la cuestión del reconocimiento pudiera tener consecuencias.
} 
64. El término "carga" (charge) significa "todo derecho de cualesquiera naturaleza y origen que pueda hacerse valer contra un buque, ya sea por medio de un embargo preventivo, un secuestro o cualquier otra vía, e incluirá los privilegios marítimos, los privilegios, los gravámenes, los derechos de uso y los derechos de retención, pero no las hipotecas". La definición de "carga" permanece sin cambios desde la segunda revisión del texto y en su $38^{\circ}$ periodo de sesiones el GT acordó mantener el texto inalterado.

65. El Instrumento, bajo la expresión "todo derecho de cualesquiera naturaleza y origen", parece adoptar un enfoque funcional de los créditos purgables: todos aquellos, de cualquier tipo (refiriéndose a su naturaleza, ya sean, entre otros, registrados o no registrados) y de cualquier modo que surjan (refiriéndose a su origen, ya sea legal o contractual), con la condición de que estos puedan hacerse valer contra el buque. Este enfoque elegido por la Convención podría responder, como lo hizo la Convención de Ciudad del $\mathrm{Cabo}^{29}$, a un "enfoque funcional" que agrupa las soluciones legales por su función (todas aquellas reclamaciones que pueden hacerse valer contra el buque), y no por su forma (ya sean embargos, pignoraciones, cargas, gravámenes, registrados o no, etc.), frente al llamado enfoque formalista, que obvia la función para centrarse únicamente en la configuración formal de las figuras jurídicas (así, une y da un tratamiento equivalente a los diferentes créditos sobre el buque y permite la simplificación del esquema dual existente de garantías en el derecho del common law y el derecho civil). Ello deja a las legislaciones nacional la tarea de determinar qué créditos cumplen esta función, independientemente de la configuración formal de las figuras jurídicas que haya otorgado la legislación nacional.

66. El Instrumento requiere dos condiciones para que estas cargas puedan considerarse dentro del alcance del efecto de título de propiedad limpio en el Instrumento:

a) que pueda hacerse valer (en las formas que se enumeran a continuación) contra un buque

b) los medios de implementación (es decir, el procedimiento para su ejecución): ya sea por medio de un embargo preventivo, un secuestro o cualquier otra vía (admitida por la ley del Estado de la venta judicial).

67. A pesar de esta aparente victoria del funcionalismo, la Convención completa la definición de "carga" enumerando una serie de elementos específicos que pueden caer dentro de la definición (entendidos a modo de numerus apertus). Así, incluirá los privilegios marítimos, los privilegios, los gravámenes, los derechos de uso y los derechos de retención, pero no las hipotecas ${ }^{30}$. En el último periodo de sesiones del GT, se ha acordado introducir una definición del término "carga inscrita" en la que se especificara el registro pertinente, de manera similar a como se había previsto en el Proyecto de Beijing original (dado que la referencia a "cargas inscritas" aparece en los artículos 4.1 a los efectos de notificación y en el artículo 7.1 como efecto de la cancelación).

68. Privilegios marítimos: Por "privilegio marítimo" (maritime lien) se entenderá todo crédito al que la ley aplicable reconozca el carácter de privilegio marítimo sobre un buque. La doctrina ha definido los créditos marítimos privilegiados como aquellos créditos "nacidos con ocasión de la navegación marítima y garantizados con privilegios", siendo esta la prerrogativa concedida por la ley a determina-

\footnotetext{
${ }^{29}$ El Convenio de UNIDROIT sobre Garantías Internacionales Mobiliarias de 2001, junto con los Protocolos sobre bienes determinados grabados con garantía (aeronaves, satélites, material ferroviario, etc.), se ha revelado como uno de los Instrumentos internacionales con mayor éxito en el panorama internacional del Derecho Privado uniforme. Las dificultades que una materia como la propuesta conllevan (especialmente la unificación de criterios entre sistemas jurídicos tan diversos en materia de garantías y derechos de propiedad) se han visto superadas por el amplio consenso del que este Convenio está disfrutando. Actualmente (mediados de 2021) cuenta ya con 83 Estados contratantes, de los cuales, una parte importante son Estados en vías de desarrollo (signo inequívoco de la generosidad que ha mostrado el texto con ciertas jurisdicciones). Sobre esta Convención, y su posible aplicación a las garantías marítimas, vid. J.P. Rodríguez Delgado, "Security Interests over Ships: From the Current Conventions to a Possible Shipping Protocol to the UNIDROIT Convention- Lege Data and Lege Ferenda", Journal of Maritime Law and Commerce, vol. 49, 2018.

${ }^{30}$ Durante los trabajos se ha reiterado la idea de que no todos los ejemplos enumerados en la versión en inglés de la definición podían traducirse fácilmente a otros idiomas.
} 
dos créditos (de ahí su denominación como "privilegiados"). Esto se traduce en la atribución a su titular de una triple facultad de persecución, realización y preferencia en la venta judicial del buque sobre el que nació el crédito y para cuya satisfacción queda aquel real y especialmente afecto en garantía (de ahí su incardinación entre los derechos reales de garantía) ${ }^{31}$.

69. Se argumenta que un crédito es privilegiado porque otorgan al acreedor un derecho de (a) realización sobre el buque (consecuencia directa de la ficción legal de que es el propio buque el sujeto infractor); (b) reipersecutoriedad, es decir, el crédito sigue al buque allí donde va, con independencia de que se modifique la titularidad, matrícula o pabellón, con excepción de las ventas forzosas; y (c) preferencia en el cobro respecto de aquellos acreedores "comunes" o hipotecarios, quebrándose de esta manera el principio par conditio creditorum.

70. El término "privilegio marítimo" es utilizado por la Convención en una dualidad de situaciones: (a) para definir el término "carga" o "gravamen" 32 (que a su vez se usa para definir el término "título de propiedad limpio"); y (b) para definir las personas a quienes por su titularidad se les notificará la venta judicial del buque (Artículo 4.1) ${ }^{33}$.

71. La redacción originaria circunscribía los "privilegios marítimos" a todos los casos reconocidos por "la ley que resulte aplicable conforme a las normas de derecho internacional privado del Estado de la venta judicial". Se cuestionó, sin embargo, la necesidad de hacer referencia en la definición a las normas de derecho internacional privado del Estado de la venta judicial ${ }^{34}$. Por ello se ha optado por definir, en su redacción actual, el término "privilegio marítimo" mediante una referencia a los privilegios marítimos reconocidos por "la ley que resulte aplicable".

72. Parece claro que para definir las personas a quienes por su titularidad se les notificará la venta judicial conforme al artículo 4, debe ser el Tribunal del Estado de venta judicial el que pudiera determinar cuáles eran los titulares de privilegios marítimos. En este sentido, la referencia a las normas de derecho internacional privado servía para aclarar que el tribunal no debía excluir automáticamente los privilegios marítimos no reconocidos por la ley del Estado de la venta judicial, sino que debía determinar la existencia de esos privilegios a la luz de la ley que los regía. Al mismo tiempo, se señaló que, a los efectos del título de propiedad limpio y, por ende, de la definición de "carga", no era necesario ni conveniente limitar los privilegios marítimos a los reconocidos por las normas de derecho internacional privado del Estado de la venta judicial (en ese contexto, debería asignarse un sentido amplio al término "privilegio marítimo").

73. A fin de evitar que se hiciera un doble uso del término en el proyecto de Instrumento (referirse a una dualidad legislativa según el privilegio se usase para definir el término "carga" -y por tanto el del título e de propiedad limpio- o bien para determinar los sujetos objeto de notificación conforme al artículo 4) se sugirió que la referencia a las normas de derecho internacional privado del Estado de la venta judicial se suprimiera de la definición de "privilegio marítimo" y se sustituyeran simplemente por "ley aplicable".

${ }^{31}$ Vid. por todos J.L Gabaldón García; J.M. Ruiz Soroa, Manual de Derecho de la Navegación Marítima, 3 Ed., Marcial Pons, Madrid, 2006, pp. 309-310.

${ }^{32}$ Si bien la definición de "carga" abarcaba los privilegios marítimos, no estaba vinculada a la ley aplicable como sí lo está la definición de "privilegio marítimo" en el artículo 2. Durante la $38^{\circ}$ sesión del GT se planteó la cuestión de si, en ausencia de ese vínculo, podría interpretarse que la definición de "carga" comprendía únicamente los derechos reconocidos por la ley del Estado del foro. El GT decidió sin embargo que no era necesario modificar la definición para hacer referencia a las cargas reconocidas por la ley aplicable.

${ }^{33}$ Un tercer elemento, referido a las personas que podían prestar la demanda o solicitud de que la venta judicial no tuviese efectos internacionales (Artículo 10), entre los que se enunciaban a los titulares de privilegios marítimos, ha sido eliminado en la tercera revisión del texto.

${ }^{34}$ A/CN.9/1007, párr. 19. 
74. Pero ¿a qué ley se refieren el Convenio con las palabras "ley aplicable"? ¿Con base en qué ley aplicable se reconoce el crédito como un privilegio marítimo? ¿A la Ley del Estado de venta judicial o a la Ley del Estado donde dicha venta producirá sus efectos -en el Estado de bandera o en el Estado de embargo posterior del buque-? En la última sesión del GT se preguntó, en palabras de la Secretaría, si quedaba claro a qué ley se hacía referencia con las palabras "ley aplicable". Se observó que esas palabras darían cabida a que se aplicaran las normas de derecho internacional privado del Estado del foro. El Grupo de Trabajo, sin embargo, acordó mantener la definición revisada sin más modificaciones.

75. Los crédito marítimos, privilegiados o no, inciden en tres momentos procesales en la venta judicial de un buque: (1) como reclamo suficiente para el embargo preventivo del buque y su posterior venta judicial (situación fuera del alcance del Instrumento); (2) como crédito purgado o purgable como consecuencia de la venta judicial del buque de conformidad con la legislación nacional del Estado de venta; (3) como crédito purgado reconocido en el Estado de efecto de la venta, a fin de otorgar los efectos del título de propiedad limpio inscrito en el Certificado y, en su caso, proceder a la denegación del embargo preventivo iniciada por un acreedor marítimo insatisfecho o indebidamente notificado.

76. El problema de los privilegios marítimos es que el Tribunal del Estado de la venta judicial, al aplicar su ley nacional para proceder consecuentemente con la venta y poder purgar todos los privilegios marítimos que pesan sobre el buque, debe, previamente, reconocerlos, para posteriormente notificar a sus titulares del procedimiento (como sucedería en una venta judicial nacional). En este proceso de reconocimiento de gravámenes marítimos privilegiados, el Tribunal aplicará, en primer lugar, su derecho interno sobre privilegios marítimos (si así lo considera) y, en segundo lugar, sus normas de conflicto de leyes (en algunas jurisdicciones, como en el Reino Unido, será la lex fori, pero en otras, como en España, la ley del pabellón del buque -con toda probabilidad, ley extranjera-).

77. El problema surgirá, en este último punto, una vez adjudicado judicialmente buque a su nuevo propietario, y se presente entonces una solicitud de embargo contra el buque en un tribunal de un Estado Parte distinto al de la venta judicial. ¿Qué sucede si un crédito marítimo sobre un buque se reconoce en el Estado de venta judicial pero no en el Estado de embargo? El Tribunal admitirá los efectos de título de propiedad limpio reconocidos en el Certificado que el comprador deberá presentar para solicitar el levantamiento del embargo preventivo el buque. El Tribunal de ese otro Estado Parte no tendrá nada que objetar al reconocimiento del efecto extintivo del crédito marítimo sobre el buque, dado que, por ser Estado Contratante del Convenio, el reconocimiento de la venta judicial será "automático".

78. Derecho de uso sobre el buque: El término "derecho de uso" (right of use) que figura en la definición de "carga" no aparece definido por el Instrumento, y esta carencia podría dar lugar a problemas interpretativos ${ }^{35}$. Durante la $37^{\mathrm{a}}$ sesión se debatió si la definición de "carga" debería incluir, como efecto de la purga, también al contrato de arrendamiento a caso desnudo (en adelante también bareboat charter). En opinión de algunas delegaciones y observadores, el hecho de que el término "carga" incluya ya el término "derecho de uso" sugiere que el bareboat charter, como derecho de uso que es, debería ser purgado para incardinarse dentro de los efectos de la venta judicial (si bien, esto es algo que debe prescribir, como indicaremos en el capítulo siguiente ${ }^{36}$, la ley nacional del Estado de venta). Si embargo,

- Si la referencia al "derecho de uso" en la definición actual de carga puede entenderse como cualquier acuerdo relacionado con el uso o arrendamiento del buque, ya esté incluido en un contrato de arrendamiento o de otro tipo, entonces la definición también cubre, no sólo los arrendamientos a casco desnudo, si no lo fletamentos por viaje o por tiempo; y todos ellos

\footnotetext{
${ }^{35}$ Algunas delegaciones han valorado incluir expressis verbis en la definición de carga el "bareboat charter that, according to the law of judicial sale, survives such sale", o alternativamente, añadir junto al derecho de uso "including bareboat charter that survives the sale". Sin embargo, creemos que esto, aunque es una posibilidad, no erradicaría el problema.

${ }^{36} \mathrm{Vid}$. Apt. IV.1A).
} 
se terminarán con la venta judicial. En otras palabras, el comprador no estará obligado por estos contratos sobre el buque previamente acordados. En este sentido, el término "arrendamiento a casco desnudo" o barebaot charter estaría incluido, a modo de numerus apertus, entre los "[...] derechos de cualesquiera naturaleza y origen que pueda hacerse valer contra un buque", en la definición de "carga" 37 .

- Sin embargo, si la intención de la Convención, debido a que el término ha sido expresamente excluido de la lista, es eximir dichos contratos, dejando su interpretación a la ley del Estado de la venta judicial (por lo que el contrato a casco desnudo -o fletamentos por tiempo/ viaje- serán o no considerado como un "derecho de uso" según cada jurisdicción), entonces, los arrendamientos registrados sobrevivirán en algunos países a la venta (en España, vid. artículos 190 y 196 LNM) y el comprador asumirá el contrato de arrendamiento existente ${ }^{38}$.

\section{Materialización de los efectos de la venta judicial}

79. El propósito del Convenio es regular los cuatro principales efectos internacionales de la venta judicial (excluyendo, a propósito, los efectos internos en el Estado de venta judicial). De los efectos comentados, tres son efectos positivos o permisivos (los que se producen en el Estado de registro del buque) y uno tiene carácter negativo o preventivo (el que se produce en cualquier otro Estado Contratante). Estos son: (a) transferir la propiedad del buque (Artículos 3 y 6); (b) cancelar todas las hipotecas y todas las cargas inscritas que graven el buque (incluidos los créditos marítimos) en el Estado del Pabellón (Artículo 7); (c) dar de baja el buque del registro (y solicitar, si se desea, que se expida un certificado de cancelación a los efectos de la nueva inscripción del buque a favor del comprador) (Artículo 7); y (d) ante la petición de embargo preventivo del buque (o cualquier otra medida similar), la capacidad para solicitar ante el Tribunal que conozca del embargo que desestime dicha petición ante la exhibición del certificado de venta judicial, o si el buque ya está embargado, solicitar que se levante dicha medida que pesa sobre el buque (Artículo 8).

\section{Efectos en el Estado del Pabellón o de Registro (actuación del registrador)}

80. Tras la presentación del certificado de venta judicial -al que se refiere el artículo 5- en un Estado Parte (en el idioma oficial del registrador o una traducción autenticada) y de conformidad con la legislación de ese Estado, el Registrador u otra autoridad competente ${ }^{39}$ deberá:

a) cancelar todas las hipotecas y todas las cargas inscritas que graven el buque,

b) dar de baja el buque del registro y emitir un certificado de cancelación a los efectos de la nueva inscripción (bajo cualquier otro pabellón);

c) inscribir el buque a nombre del comprador, si este así lo solicita, y

d) actualizar el fichero registral añadiendo cualquier otro dato pertinente que conste en el certificado de venta judicial

${ }^{37}$ Así, P. KRAGIC, “About the concept of Convention on judicial sale of ships”, Vol. 55, ETL, 4/2020, párr. 17, quien considera el alquiler a casco desnudo como una carga.

${ }^{38}$ En este sentido, podría considerarse que la relación contractual otorga al fletador a casco desnudo un derecho a poseer y utilizar el buque superior al derecho del comprador tras la venta judicial. Derecho que podrá hacerse efectivo tras la venta judicial ante el nuevo comprador. Algunas delegaciones han propuesto introducir una aclaración en la Nota Explicativa que explique que en la noción de "derecho de uso" de la definición de "carga" debe incluirse también el arrendamiento a casco desnudo.

${ }^{39}$ Se ha insertado la palabra "competente" como calificativo de "Registrador" para aclarar que puede haber más de un Registrador en un Estado Parte (A/CN.9/WG.VI/WP.87, nota 32). Esta es la situación en España, como en otras muchas jurisdicciones, donde nuestro sistema dual obliga a inscribir el buque en el Registro de Matrícula -que otorga la nacionalidad- y en el Registro de Bienes Muebles, en el que se registras las cargas y gravámenes sobre el buque. 
81. Este efecto no se aplicará si un tribunal del Estado del registrador u otra autoridad determina, en virtud del artículo 10, que el efecto de la venta judicial sería [manifiestamente] contrario al orden público de ese Estado (Artículo 7.5).

\section{A) Venta judicial de un buque arrendado a casco desnudo}

82. La deuda por la que se solicita el embargo y posterior venta judicial de un buque puede provenir, en el caso de un arrendamiento a casco desnudo -bareboat charter-, bien del propietario/armador o del arrendatario. En el caso del propietario del buque, la venta será exigida por los acreedores hipotecarios garantizados (generalmente, instituciones financieras ante el impago de la hipoteca) o por los reparadores de buques en caso de que el contrato a casco desnudo imponga este deber al propietario o armador. En el caso del arrendatario, la venta será exigida por los acreedores con créditos garantizados por un privilegio -los lienholders o acreedores marítimos- (generalmente como consecuencia de impagos de sueldos a la tripulación, impagos de tasas portuarias, etc.).

83. Sin embargo, un tema que a nuestro juicio queda pendiente es si el arrendamiento a casco desnudo debe considerarse un "derecho" o "carga" a efectos de "título de propiedad limpio" que otorga la Convención al comprador tras la venta, o si, por el contrario, estamos ante un "contrato" que pervive a la venta judicial ${ }^{40}$. ¿Está el comprador obligado, en algunas jurisdicciones, a cumplir con el arrendamiento existente (y, por lo tanto, no puede tomar posesión en el buque tras la venta), o podría invocar la Convención y solicitar al Estado de la venta judicial un Certificado que confirme su "título de propiedad limpio", incluso del arrendamiento, sobre el buque adquirido? Una u otra decisión hará que los arrendatarios pueden verse en una posición vulnerable si el contrato se rescinde con ocasión de la venta judicial ${ }^{41}$.

84. En términos similares al MLMC 1993, el Instrumento establece que en los supuestos en los que el buque estuviese inscrito en un Estado Parte bajo un contrato de arrendamiento a casco desnudo (que no es el Registro de bandera original debido al cambio temporal de pabellón), el Registrador competente ( $u$ otra autoridad competente) dará de baja el buque del registro y expedirá un certificado de cancelación de la inscripción a petición del comprador (Artículo 7.2). Con este certificado de cancelación, el nuevo propietario podrá solicitar al registrador en el originario Estado de abanderamiento la cancelación de cualquier hipoteca o carga registrada sobre el buque y la eliminación del buque del Registro.

85. Esta disposición se basa en el hecho de que el arrendamiento se termina con la venta judicial. No obstante, si en el Estado de la venta tal trámite no extingue la relación contractual entre el propietario y el fletador/armador, el arrendamiento seguirá existiendo y, por tanto, la venta no quedará sujeta a los efectos de la Convención (dado que esta no otorgará un título de propiedad limpio al comprador). Durante las discusiones del GT, se señaló que, en algunas jurisdicciones (como por ejemplo España, Japón o Alemania), los derechos de los arrendatarios a casco desnudo (el derecho de uso o right of use) sobreviven a una venta judicial ${ }^{42}$, incluso aunque en estas jurisdicciones, la mayoría de las ventas judiciales resultarán en la concesión de un título limpio de propiedad ${ }^{43}$. En otros ordenamientos jurídicos,

\footnotetext{
${ }^{40}$ Se ha sostenido por parte de la doctrina que los eventuales contratos de arrendamiento a casco desnudo sobre el buque han de tenerse por cancelados tras la venta judicial (J. Franco Arias, “Artículos 480 a 486 ”, en J.A. Rueda Martínez/I. Arroyo (Dirs.), Comentarios a la Ley 14/2014, de 24 de julio, de Navegación Marítima, Aranzadi, 2016, p. 1444), si bien hay también posiciones contrarias (F. BerLINGIERI, "The 1993 Convention on Maritime Liens and Mortgages", LMCLQ, 1995, p. 71).

${ }^{41}$ Cuando se llega a una situación de venta judicial del buque, lo más importante, por el bien de todos los interesados, es que el buque se venda al mayor precio posible y en el menor tiempo, ya que un buque embargado, atracado en puerto, tiene un coste diario muy elevado (tasas portuarias, mantenimiento, asesores, peritos, etc.). Sin embargo, pese a esta urgencia, parece evidente que el arrendatario a casco desnudo es ajeno a las circunstancias que motiven la venta judicial, y sin embargo podrá verse afectado por esta.

${ }^{42}$ A/CN.9/1007, par. 44.

${ }^{43}$ El Artículo 11 de la Convención sobre privilegios marítimos e hipoteca naval de 1967 establece, en términos similares a los enunciados, que "ningún contrato de fletamento o contrato para el uso del buque se considerará un gravamen o carga a los
} 
los arrendamientos pueden considerarse un "derecho" (interest o right of use), que obviamente se liquida con la venta judicial, otorgando al comprador un buque libre de todas las cargas.

86. En lo que respecta a la legislación española, "en caso de enajenación del buque [en virtud de un negocio jurídico en el que se incluyen las ventas judiciales], el adquirente quedará subrogado en el contrato de arrendamiento existente, siempre que estuviese inscrito en el Registro de Bienes Muebles o conociese efectivamente su existencia al tiempo de la venta. En otro caso, quedará extinguido el contrato, con independencia del derecho del arrendatario a ser indemnizado por el arrendador" (Artículo 196 LNM). En consecuencia, el arrendamiento a casco desnudo no se extinguiría con la venta -a pesar de las cláusulas contractuales que pudieran existir en el contrato de arrendamiento ${ }^{44}$.

87. El artículo 196 utiliza el término "enajenación" para delimitar los casos a los que se aplica la subrogación se establece explícitamente a continuación en el contrato de arrendamiento de buque por parte del adquirente. Este término, ciertamente confuso, podría interpretarse de diversas maneras: (1) la referida únicamente a la transmisión voluntaria, (2) la referida a la venta forzosa del buque, o (3) en referencia a cualquiera de los negocios traslativos de la propiedad del buque. Si optásemos por la primera, la venta judicial tendría como efecto sobre el contrato de arrendamiento de buque que este quedaría extinguido (como si el contrato fuese tratado como uno más de los derechos -de uso en este caso- que se purgan con la venta judicial). Por el contrario, si optásemos por la segunda o tercera de las opciones, el adquirente quedará subrogado (por subrogación legal) en el contrato de arrendamiento existente, siempre que estuviese inscrito en el Registro de Bienes Muebles.

88. La Legislación marítima parece optar por esta segunda interpretación ya que el término utilizado en el artículo 196 LNM (“enajenación”) es el escogido en la Exposición de Motivos de la Ley (epígrafe XI) para referirse también a la venta judicial: "En el capitulo III se regula (...) la venta forzosa del buque, sea judicial o administrativa, articulándose como una especie de «purga» respecto de todos los gravámenes que sobre el mismo pudieran pesar. Se basa en un adecuado sistema de publicidady notificaciones -que en el caso de hipotecas al portador y privilegios de titular desconocido sólo son posibles a favor de quienes hubieran comunicado la existencia del crédito- antes de proceder a la enajenación". Parece evidente que el Legislador, mediante el uso de este término en ambas localizaciones, ha querido referenciar los efectos subrogatorios del artículo 196 LNM también a la venta judicial. Igualmente, la LPEMM, al referirse a la venta en pública subasta de un buque abandonado (Artículo 302 LPEMM) utiliza el término "enajenación" a la hora de indicar el destino donde remitir el producto de dicha subasta judicial.

89. En España, por tanto, el arrendamiento a casco desnudo no se extingue con la venta judicial, por lo que una venta conducida en nuestro país, o en jurisdicciones similares, puede presentar sobre el texto de la Convención algunas particularidades:

90. Venta de un buque español en el extranjero: Si la venta judicial se lleva a cabo en una jurisdicción distinta a la española, el Tribunal de la venta, si bajo su legislación nacional el bareboat charter es un "rigth of use" purgable con la venta, emitirá el Certificado con la intención de acreditar efectos extintivos en nuestro país (porque bajo la legislación del Estado de la venta, el arrendamiento es considerado una "carga"). Cuando el comprador acuda al Registrador español para cancelar el buque del Registro de abanderamiento temporal, previa presentación del certificado deberá notificarle de la

efectos de este Artículo". Los Travaux Préparatoires del MLMC 1993 contenían una declaración similar en el artículo 12 con la intención de aclarar que la regla por la cual todos los "gravámenes" tras la venta dejan de gravar al buque no implicaba que un contrato de arrendamiento de buque existente no fuese vinculante para el comprador. El CMI sugirió, sin embargo, que se suprimiera esta disposición.

${ }^{44}$ En este sentido, entre otros, J.L. García-Pita y Lastres, Arrendamientos de buques y derecho marítimo Con especial referencia al Derecho de Formularios, Tirant, Valencia, 2006, p. 913. 
existencia de este contrato de arrendamiento a casco desnudo inscrito, y la posible subrogación en el mismo. Sin embargo, entendemos que la primacía del Convenio internacional (por medio del Certificado), permitirá al nuevo propietario solicitar la cancelación registral del arrendamiento a casco desnudo (pese al mencionado artículo 196).

91. Venta de un buque extranjero en España: Si la venta judicial se realiza ante nuestros órganos judiciales, la purga total de créditos dependerá de la consideración que tengamos del bareboat charter.

A) Si este es considerado un "right of use" y es incardinado dentro del término "carga" del Convenio, dado el contenido del artículo 196 LNM -y siendo la ley del Estado de venta la española la que determinará le título de propiedad limpio-, este no se extinguirá con la venta judicial, tal y como hemos anticipado. Es por ello por lo que el Tribunal no emitirá el certificado conforme al artículo 5, y esta venta no podrá desplegar sus efectos internacionales (especialmente en el Estado de Registro del buque, que, para poder cancelar la matrícula, deberá reconocer extraconvencionalmente la venta conducida en nuestro país), quedando fuera del alcance internacional del Instrumento. Ello no impide, sin embargo, que la venta judicial sea válida y suponga una transferencia de propiedad sobre el buque en favor del nuevo comprador ${ }^{45}$.

$\mathrm{Si}$, como hacen algunos autores ${ }^{46}$, interpretan los artículos 190 y 196 única y exclusivamente para la venta privada (en lugar como defendemos aquí en favor de todo tipo de enajenación), entonces parece lógico que el arrendamiento a casco desnudo sufra el mismo destino que el resto de las cargas en caso de venta judicial. En cualquiera de los casos, la polémica está servida.

B) Si este contrato no es considerado una "carga" según la Convención, entonces su supervivencia tras la venta es indiferente. Por ello, el Tribunal podrá emitir un certificado conforme al artículo 5, documentando que la venta ha otorgado al comprador un título de propiedad limpio de todas las cargas y gravámenes anteriores -nuevamente, a excepción del contrato de arrendamiento a casco desnudo-. Con este Certificado, el nuevo comprador podrá solicitar la cancelación en el Registro del Estado de abanderamiento temporal del buque. El Registrador de este Estado Contratante, ante la presentación del certificado, procederá a cancelar dicho registro. Esta venta judicial entrará dentro del ámbito de aplicación del Convenio.

92. Venta de buque español en España: Nos encontramos en una situación similar a la prevista anteriormente. Todo dependerá de la consideración del barebaot charter, con la diferencia de que el Registrador que dará efecto al posible Certificado de venta judicial que se emita será también español. Según sea la consideración del bareboat, la solución será una u otra de las ya contempladas.

93. Parece evidente, por tanto, que (1) la calificación del contrato de arrendamiento a casco desnudo como "derecho de uso" incardinando dentro del término "carga" es la cuestión nuclear para resolver el problema al que nos hemos referido y (2) que dicha calificación dependerá exclusivamente, porque así lo ha decidido la Convención, de la legislación del Estado de la venta judicial.

\footnotetext{
${ }^{45}$ En ese tipo de situaciones, España (y otras jurisdicciones como Alemania o Japón) no será un escenario amigable para el comprador en el que se lleve a cabo una venta judicial de buque. Véase, sin embargo, sobre la posible modificación del régimen legal, párrafos 95 y ss. de este artículo. Si el arrendamiento a casco desnudo se considerase una "carga" a efectos de la Convención, bajo el término "derecho de uso", y el comprador desease asumir ese contrato existente, para continuar obteniendo ingresos económicos sobre el buque arrendado, esa venta judicial no estaría sujeta al ámbito de aplicación de la Convención.

${ }^{46}$ J. Franco Arias, “Artículos 480 a 486”, en J.A. Rueda Martínez/I. Arroyo (Dirs.), Comentarios a la Ley 14/2014, de 24 de julio, de Navegación Marítima, Aranzadi, 2016, p. 1.444.
} 
94. Incluir en la definición de "carga/charge" el término "bareboat charter"47, aunque es una posibilidad, creemos, no erradicaría, al menos en nuestro país, el problema. Sin embargo, esto puede hacer que algunos Estados se opongan a la ratificación del Convenio, ya que, si el texto menciona que el arrendamiento a casco desnudo debe ser considerado una "carga" purgable bajo el efecto del Convenio, algunas jurisdicciones se verán forzadas a enmendar su legislación interna y adaptar sus normas al texto uniforme para poder mantener la aplicación del Convenio cuando exista un contrato de arrendamiento vigente en el momento de la venta. Es muy posible que después de tal discusión, las leyes de los respectivos Estados que reconocen el principio romano bien establecido "emptio non tollit locatum" quieran enmendar su legislación y decir explícitamente que una venta judicial de un buque pone fin a cualquier arrendamiento. En caso contrario, existirá un desequilibrio entre la legislación interna -en la que el arrendamiento sobrevive a la venta- y el Convenio internacional -que sólo resultaría aplicable si el bareboat charter no obliga al comprador-.

95. Todo lo dicho hasta aquí es sobre la base de la normativa actual (mediados de 2021). Sin embrago, fruto de las negociaciones en el Grupo VI de UNCITRAL sobre el futuro Convenio sobre reconocimiento de las ventas judiciales de buques, en cuyas deliberaciones España está participando, la Asociación Española de Derecho Marítimo (AEDM) ha presentado a la Dirección General de la Marina Mercante una propuesta de reforma del artículo 196 anteriormente mencionado (con la intención de que esta sea introducida en el Anteproyecto de Ley de reforma del Texto Refundido de la Ley de Puertos del Estado y de la Marina Mercante y de la Ley de Navegación Marítima que se está actualmente tramitando). La AEDM entiende que "la norma prevista en el artículo 196 de la LNM debe limitarse a los supuestos de venta voluntaria del buque y no a los supuestos de su venta forzosa. Lo que se pretende es que cualquier adquirente de un buque en sede de ejecución forzosa pueda obtener la propiedad del buque libre de cargas, tal como prevé la LNM, y además su posesión al margen de los efectos del contrato de arrendamiento en vigor en el momento de la venta (figure dicho contrato inscrito en el Registro de Bienes Muebles o no)". Para ello se propone un nuevo párrafo al artículo 196: "Este régimen no será aplicable en los supuestos de venta forzosa del buque, en pública subasta, judicial o notarial, en cuyo caso quedará extinguido el contrato, sin perjuicio de los derechos que puedan corresponder al arrendatario frente al arrendador" ${ }^{\prime 4}$.

96. En caso de que este precepto fuese enmendado, España se situaría entre aquellos Estados en los que la venta judicial de un buque no sólo purga por completo todas las cargas y gravámenes sobre el buque, sino que además extingue los contratos de arrendamiento a casco desnudo sobre el buque, convirtiéndose ahora si, en un escenario amigable para compradores en el que proceder a la venta judicial de buques.

97. Pese a todo lo anterior, algunos autores han señalado, sin embargo, que este tipo de situaciones serán extremadamente raras en la práctica ${ }^{49}$, dado que si es el propietario quien tiene la deuda objeto de la venta judicial, será infrecuente que se lleve a cabo una venta contra el buque, debido a que en algunos casos el arrendatario a casco desnudo paga el hire directamente al banco en lugar de al propietario (como garantía del préstamo), lo que hace inusual las deudas del propietario con los acreedores hipotecarios.

\footnotetext{
${ }^{47}$ Véase Cl. 19 SALEFORM 2012.

${ }^{48}$ Evidentemente este nuevo régimen que se propone, lo es sin perjuicio de los derechos del arrendatario del buque frente a su armador.

${ }^{49}$ Una cuestión que resulta también controvertida, además de la mencionadas con anterioridad, es la posible primacía de las cláusulas contractuales que en él pudiesen existir. Así, por ejemplo, la cl. 25 BARECON establece que en el caso de que los propietarios sean privados de la propiedad del buque por adquisición obligatoria (habría que ver si la venta judicial estaría aquí incluida), el arrendamiento se considerará terminado. Aunque BIMCO ha introducido dos nuevas cláusulas en el formulario BARECON que tratan de la terminación y la reposesión o recuperación del buque, ni la una ni la otra se aplican expresamente a la terminación del contrato por razón de adquisición obligatoria. ¿Prima entonces la voluntad de las partes sobre el texto del artículo 196 LNM? Ante el aparente carácter dispositivo de las normas sobre arrendamiento de buques de la LNM, parecería que la respuesta debería ser aquí afirmativa.
} 


\section{Efectos en otro Estado Parte (no se puede volver a embargar el buque después de la venta judicial)}

98. El artículo 8 del Proyecto de Convención, al abordar el efecto de denegación o levantamiento del embargo preventivo del buque, contempla dos posibles escenarios que podrían presentarse ante la situación en la que un demandante (por ejemplo, un acreedor al que no se notificó adecuadamente la venta) decide entablar una acción ante un órgano judicial de un Estado Parte en virtud de un crédito nacido antes de una venta judicial del buque y que no ha sido satisfecho tras ella.

- Escenario 1: Si se solicita el embargo preventivo de un buque o cualquier otra medida similar en virtud del crédito mencionado, el Tribunal desestimará la solicitud si se le exhibe el certificado de venta judicial mencionado en el artículo 5 (en el idioma oficial del órgano judicial o una traducción autenticada).

- Escenario 2: Una vez que el Tribunal de un Estado Parte ha ordenado embargar el buque en virtud de un crédito nacido antes de una venta judicial anterior del buque, y éste ha sido efectivamente embargado (o se ha tomado una medida similar), el órgano judicial ordenará que se levante la medida que pese sobre el buque si se le exhibe el certificado de venta judicial mencionado en el artículo 5.

99. Ambas medidas no se aplicarán si un tribunal de un Estado Parte determina:

a) que desestimar la solicitud u ordenar que se levante la medida, según sea el caso, sería manifiestamente contraria al orden público de ese Estado; o

b) que la existencia de alguna de las circunstancias previstas en el artículo 10 (este artículo ha sido recientemente modificado - A/CN.9/WG.VI/WP.90-, eliminado los motivos que impedían que la venta judicial surtiese efectos internacionales, a saber, que el buque no se encontraba físicamente dentro del territorio del Estado de la venta judicial en el momento de la venta, que en la venta medió fraude cometido por el comprador; o que los efectos serían manifiestamente contrarios al orden público de ese otro Estado parte $\left.{ }^{50}\right)$. Es por ello que, por ahora, el artículo 10 no tendrá incidencia sobre la inaplicación de este efecto de la venta judicial.

\section{Circunstancias en las que una venta Judicial no surte efectos internacionales ${ }^{51}$}

100. Los efectos liberatorios y extintivos de la venta judicial en otro Estado Parte constituyen, sin lugar a duda, una de las mayores innovaciones con respecto al MLMC 1993. Sin embargo, también puede suponer uno de los aspectos más conflictivos del texto internacional, especialmente por el riesgo que pueda ocasionar para los acreedores indebidamente notificados el reconocimiento automático en el Estado de Matrícula de los efectos internacionales de la venta efectuada en otro Estado, desconociendo cualquier procedimiento formal de reconocimiento y ejecución de decisiones judiciales extranjeras. Por tanto, la posibilidad de denegar los efectos internacionales, tal como se contiene en el Proyecto de Instrumento, es de suma utilidad para el Registrador (Artículo 7) y el Tribunal competente (Artículo 8) si este procedimiento es (manifiestamente) contrario a su orden público (habrá que estar a lo que los tribunales aleguen como causas de denegación por orden público, pero entre estas podría estar, una inadecuada notificación -conforme a su legislación interna- a los acreedores no registrados) ${ }^{52}$.

${ }^{50}$ El GT estimó que el motivo relativo a que el buque no se encontrase físicamente dentro del territorio del Estado de la venta era superfluo, dado que ya se utilizaba para definir el ámbito de aplicación del Proyecto de Convención. Por otra parte, se señaló también que el motivo para denegar los efectos relativos a la mediación de fraude por el comprador durante la venta no era necesario, dado que podría ser difícil demostrar el fraude en un Estado que no fuera el Estado de la venta judicial por falta de pruebas (A/CN.9/1007, párr. 81). Tras deliberar, el Grupo de Trabajo convino en suprimir ambos motivos.

${ }^{51}$ La MLMC 1993 no contiene disposición similar como la que se encuentra en el artículo 10 del Proyecto de Instrumento, especialmente con la prevista con anterioridad a su última modificación en abril de 2021.

${ }^{52}$ La notificación errónea o indebida a una de las partes afectadas de conformidad con el artículo 4 no figura en la Con- 
101. Parece que un artículo -el artículo 10- centrado en las circunstancias en las que la venta judicial no tiene efectos internacionales en otros Estados Parte no tiene espacio en el Instrumento, más que para repetir condiciones ya mencionadas. Si los artículos 3 (ámbito de aplicación), 4 (notificación de la venta), 6 (efectos internacionales), 7 (acción del registrador) y 8 (acción del Tribunal competente) establecen los requisitos de aplicación de la Convención, así como los de sus efectos, parecería obvio que la falta o incumplimiento de estos significaría que el Convenio no se aplicará a esas ventas o que sus efectos internacionales no se producirán. Por tanto, no sería necesaria una disposición dedicada a reiterar las mismas circunstancias.

\section{Consideraciones finales}

102. La venta o subasta judicial de buques y la distribución del producto de la venta a los acreedores representan el capítulo final de cualquier procedimiento de ejecución de hipoteca naval u otras deudas marítimas (Artículo 486 LNM). Sin embargo, existe un riesgo real si la venta no ha sido debidamente notificada en el que los acreedores marítimos indebidamente notificados intenten embargar el buque en un puerto de su conveniencia para volver a presentar reclamo por su crédito, lo que genera una más que posible incertidumbre entre los compradores a la hora de presentar una oferta de venta. Sin embargo, la consideración por el GT de los requisitos de notificación (Artículo 4) y la creación de un Repositorio internacional y en línea (Artículo 12) asociado con el Global Integrated Shipping Information System (GISIS) de la OMI, al cual deberán enviarse las notificaciones y certificados emitidos en virtud de los Artículos 4 y 5 para su publicidad online, podrá resolver satisfactoriamente, en cierta medida, el antiguo reclamo por los acreedores marítimos (no registrados), dado que al alcance de un solo clic podrán conocer la situación del buque sobre el que ostentan un crédito no satisfecho.

103. Para tratar de paliar este posible efecto disuasorio, la venta judicial debe extinguir todas las hipotecas y gravámenes existentes sobre el buque y otorgar un título de propiedad limpio al adquirente. Solo entonces será posible asegurar el mejor precio posible en la subasta judicial del activo, en beneficio de todas las partes implicadas. El efecto purgativo de la venta (asegurando que el comprador pueda dar de baja el buque de su bandera anterior, pudiendo registrarlo en uno nuevo Registro a su elección, y que el buque pueda navegar por todo el mundo sin preocupación ante un posible embargo por créditos anteriores) logrará también un mayor número de postores y, por lo tanto, lo que sin duda incrementará el valor final del buque. No obstante, existen algunos aspectos relevantes en diferentes jurisdicciones que pueden hacer que estas ventas judiciales "limpias" queden fuera del alcance de la Convención (especialmente en aquellas jurisdicciones donde se permiten las ventas judiciales con subrogación de compradores).

104. Por último, pero no menos importante, este título de propiedad debe poder ser reconocido y ejecutado en todo el mundo. El certificado emitido por el Tribunal a solicitud del adquirente tras la venta judicial permitirá que esta venta pueda ser reconocida y el título ejecutado en todos los Estados Contratantes.

105. El Proyecto de Instrumento internacional no tiene por objeto el reconocimiento de las decisiones de venta de un buque en otro Estado (ya existen instrumentos internacionales para este propósito), sino el reconocimiento de los "efectos internacionales de una venta judicial", siempre que dicha venta produzca una purga total sobre el buque. En otras palabras, esta Convención es un "espejo" en el que se

vención como motivo expreso de denegación de los efectos internacionales. Durante la primera sesión del GT, se sugirió que el Instrumento incluyera un motivo basado en la notificación errónea de conformidad con el artículo 4 (A/CN.9/973, párr. 63). Sin embargo, se ha decidido no introducirlo en la versión actual. La razón podría estar en que el GT no quiere inmiscuirse en la complejidad de verificar por parte de los tribunales las comunicaciones o notificaciones al registrador o al tribunal extranjero de un Estado Parte que no sea el Estado de la venta. 
deben mirar las ventas judiciales que se realicen en un Estado Contratante -realizadas de acuerdo con su legislación nacional-. De existir absoluta coincidencia entre el título de propiedad limpio otorgado con lo establecido al efecto por el Convenio, esa venta judicial podrá expandir sus efectos internacionales sobre el adquirente en el resto de los Estados Parte. No obstante, si la venta judicial efectuada al amparo de la ley del Estado de la venta, por cualquier motivo, no otorga una purga total de los créditos, según lo previsto por la Convención, entonces dicha venta, a pesar de ser totalmente válida y efectiva en el Estado en que se ha llevado a cabo, no podrá expandir sus efectos internacionales en el resto de Estados Contratantes (excepto sobre la base de los acuerdos de reconocimiento bilateral/regional de sentencias extranjeras).

106. El futuro Convenio debe favorecer un justo equilibrio entre los derechos de los acreedores existentes y los derechos del comprador en la venta judicial. La adopción de reglas uniformes para regular las ventas judiciales promoverá la armonización y unificación internacional de la ley en esta área; reducirá los obstáculos legales, contribuyendo a la seguridad económica y jurídica; aumentará los precios de las subastas judiciales; y salvaguardará significativamente los intereses de los compradores de buena fe (sin olvidar una protección adecuada a todas las partes afectadas, incluidos los acreedores marítimos). 